\title{
Information Frictions, Internet, and the Relationship between Distance and Trade
}

\author{
By Anders Akerman, Edwin Leuven, and Magne Mogstad*
}

We examine how the adoption of information communication technology affects bilateral trade. The context is a public program in Norway that rolled out broadband access points leading to plausibly exogenous variation in the availability and adoption of broadband by firms. We find that broadband makes trade patterns more sensitive to distance and economic size. These results are consistent with a model of trade with variable elasticity of demand. The model predicts that adoption of a technology that lowers information frictions enlarges the choice set of exporters and importers. This makes demand more elastic with respect to trade costs and thus distance. (JEL D83, F14, L86, O33)

\begin{abstract}
Tow do trade costs impede international trade? This question is typically analyzed in models with perfect information, examining the importance of variable trade costs (e.g., transport costs, tariffs) and fixed trade costs (e.g., setup costs, bureaucracy). An increasing body of work, however, points to the importance of imperfect information. International trade may be distorted because of information frictions, and advancements in information communication technology (ICT) could therefore promote trade and change trade patterns. Recently, policymakers and researchers emphasize that adoption of Internet in firms may affect international trade by reducing information asymmetries, lowering matching frictions between producers and consumers, or enabling better overview and planning of global supply chains (e.g., Rauch and Trindade 2003, Freund and Weinhold 2004, Choi 2010, UNESCO 2012). It is also claimed that the Internet should reduce the importance of distance and therefore benefit remote and developing countries (e.g., Friedman 2005). However, there is little evidence to substantiate these claims.
\end{abstract}

\footnotetext{
*Akerman: Department of Economics, Stockholm University (email: anders.akerman@gmail.com); Leuven: Department of Economics, University of Oslo, Statistics Norway, and CEPR (email: edwin.leuven@econ.uio. no); Mogstad: Department of Economics, University of Chicago, Statistics Norway, and NBER (email: magne. mogstad@gmail.com). Alexandre Mas was coeditor for this article. We gratefully acknowledge valuable comments from two anonymous referees, Gene Grossman, Elhanan Helpman, Ralph Ossa, Gianmarco Ottaviano, Stephen Redding, Felix Tintelnot, Giovanni L. Violante, Yuan Zi as well as seminar participants at Princeton University, the "Public Economic Policy Responses to International Trade Consequences" Workshop in Munich, the NOITS workshop in Reykjavik, the pre-ERWIT workshop in St Gallen, the EITI workshop in Sapporo, Orebro University, and Oslo University.

Go to https://doi.org/10.1257/app.20190589 to visit the article page for additional materials and author disclosure statement $(\mathrm{s})$ or to comment in the online discussion forum.
} 
Our paper contributes by analyzing how and why ICT affects bilateral trade flows. Our context is the adoption of broadband Internet in Norwegian firms over the period 2001-2008. Norway is a small open economy with segmented local labor markets. A public program with limited funding rolled out broadband access points and provides plausibly exogenous variation in the availability and adoption of broadband Internet in firms. Our analysis employs panel data with detailed information on Norwegian firms with regards to their production, technology, and trade. We use these data to empirically examine how Internet adoption in firms affects bilateral trade patterns, before developing a model that helps interpret the empirical findings.

In Section I, we describe the data. Our analysis employs several data sources that we can link through unique identifiers. Annual accounts provide data on input factors and output, custom records and intra-EU declarations give information on exports and imports, and survey data provide information on the availability and adoption of broadband Internet. In Section II, we describe the source to exogenous variation in broadband availability and adoption. Following Bhuller et al. (2013), our research design takes advantage of a public program aimed at ensuring broadband access at a reasonable price to all households throughout the country. ${ }^{1}$ Because of limited funding, access to broadband was progressively rolled out, so that the necessary infrastructure (access points) was established in different municipalities at different times. We document that the staged installation of broadband infrastructure generates spatial and temporal variation in broadband availability and, consequently, adoption (even conditional on year and municipality fixed effects).

In Section III, we describe the empirical model and estimation approach. We specify a gravity equation for the trade flows between firms in different municipalities of Norway and other foreign countries. The basic gravity equation is frequently used to analyze the determinants of bilateral trade based on the economic size of markets and the distance between two areas. ${ }^{2}$ To capture how Internet adoption affects the bilateral trade patterns, we augment the gravity equation with an indicator for broadband adoption in firms and interaction terms between broadband adoption and the determinants of trade flows.

To address the potential endogeneity of broadband adoption, we use the temporal and spatial variation in the availability of broadband Internet to construct instruments for broadband adoption and the interaction terms. Given that we control for municipality-country fixed effects and calendar time fixed effects, the identification is similar in spirit to a difference-in-difference design. The key threat to identification is therefore that the timing of the broadband rollout might be related to different underlying trends in the trade patterns across municipality-country pairs. We demonstrate that the timing does not appear to be systematically related to key

\footnotetext{
${ }^{1}$ While our analysis uses a similar identifications strategy as Bhuller et al. (2013), we apply it to a distinct question and set of outcomes. Bhuller et al. (2013) use the rollout of broadband Internet to study how Internet use affects sex crimes. Akerman, Gaarder, and Mogstad (2015) use the same strategy to study how adoption of broadband in firms affects workers' wages and labor productivity. While it is possible that the relative productivity of skilled workers is correlated with trade behavior, it is hard to use the previous literature on the skill set of employees, ICT, and trade patterns to form good and unambiguous priors on what the findings from Akerman, Gaarder, and Mogstad (2015) would imply for trade patterns with respect to distance.

${ }^{2}$ See Head and Mayer (2014) for a review of the large literature using gravity equations to analyze the pattern of international trade.
} 
observable correlates of trade, and we further challenge our identification strategy in a number of ways that show that our results are robust across a variety of specifications and samples.

The empirical results are presented in Section IV. We find that adoption of broadband Internet makes trade patterns more sensitive to distance and economic size. Going from no broadband availability to full coverage increases the magnitude of the elasticity of trade with respect to distance by 0.12 and the elasticity of trade with respect to destination size by 0.06 . For distance, this means that an increase in Internet availability of 10 percentage points increases trade for a country at the twenty-fifth distance percentile by 1.1 percent more than for a country at the seventy-fifth distance percentile. The same difference for the size (GDP) of a destination is 2.1 percent. We show that our estimates do not change appreciably if we exclude the major cities, if we include a large set of time-varying controls for potential supply and demand factors, and if we allow for different time trends across areas.

In Section V, we explore several possible mechanisms for how Internet adoption in firms may affect bilateral trade patterns. One explanation is that broadband Internet reduces information frictions and increases the choice set of exporters and importers, making it easier to substitute if a specific market becomes more expensive to export to or import from. This argument can be traced back to Marshall's first rule of derived demand: "The demand for anything is likely to be more elastic, the more readily substitutes for the thing can be obtained" (Yeung 1972, 511). We formalize this argument in a model of international trade with variable elasticity of demand and information frictions. We model information frictions as restrictions on the access to markets with which a region can trade, similar to how Arkolakis (2010) views the role of marketing to reach foreign consumers.

The model predicts that adoption of a technology that lowers information frictions enlarges the choice set of exporters and importers, and, therefore, increases the degree of competition. This makes demand more elastic with respect to bilateral trade costs and, as a consequence, increases the magnitude of the elasticity of trade with respect to distance. A corollary of this prediction is that the Internet-induced change in elasticities should be more pronounced for products for which information costs are more salient. Since information is arguably more important for trade in differentiated goods than for trade in homogeneous goods (as argued by Rauch 1999), we estimate the augmented gravity equations separately for trade flows in these two types of goods. Consistent with broadband Internet changing trade patterns through lowering information frictions, we find stronger effects of broadband adoption on the trade pattern of differentiated goods as compared to homogeneous goods.

Although the comparative statics predictions from our model are consistent with our empirical findings, several mechanisms outside our model could also explain why adoption of broadband Internet increases the sensitivity of trade to distance. For example, the direct effect of Internet on bilateral trade flows may be stronger for destination countries with similar language (see, e.g., Blum and Goldfarb 2006). Countries with similar language are closer in distance. We examine this mechanism by including controls for language similarity and its interaction with broadband Internet in the empirical model. However, adding these controls does not materially change the estimated coefficient on the interaction term between broadband 
adoption and distance. Another possibility is that the direct effect of Internet on bilateral trade flows may be stronger if the destination countries themselves have high Internet penetration (see, e.g., the theory of two-sided markets of Rochet and Tirole 2006). Empirically, countries closer to Norway tend to have higher Internet penetration. To examine this mechanism, we add Internet penetration in the destination country and its interaction with broadband Internet to the empirical model. The estimated coefficient on the interaction term between broadband adoption and distance barely moves.

Our findings are at odds with the notion that advancements in ICT would be "the death of distance." The argument was popularized by Cairncross (1997) and Friedman (2005), who claimed that modern technology makes the world "flat" and location largely irrelevant. However, there is limited scientific evidence to substantiate these claims. Indeed, Disdier and Head (2008) perform a meta-analysis of 1,000 gravity equations and find that the magnitude of the estimated coefficient on distance has increased since the 1970s, a finding often referred to as the "distance puzzle" or, in the words of Coe et al. (2002), the "missing globalization puzzle." Berthelon and Freund (2008) corroborate this result and find that the elasticity of trade to distance increased in absolute value by about 10 percent since $1985 .{ }^{3}$ Based on this evidence, Leamer (2007) argues that advancements in ICT since the 1970s have failed to reduce information frictions between countries.

Our study suggests this conclusion may be unwarranted: We provide both theory and evidence suggesting that adoption of a technology that lowers information frictions actually increases the magnitude of the elasticity of trade with respect to distance. In other words, our results suggest the "distance puzzle" may not be a puzzle after all. Adoption of a technology that lowers information frictions enlarges the choice set of exporters and importers, making it easier to substitute if a specific market becomes more expensive to export to or import from. As a result, demand becomes more elastic with respect to differences in trade costs across markets, such as geographic distance.

Our findings complement a small set of studies (Blum and Goldfarb 2006; Hortaçsu, Martínez-Jerez, and Douglas 2009; Lendle et al. 2015) examining the role of geographical distance in online markets. This evidence is mixed, and because the products, trade costs, sellers, and buyers may be very different across markets, it is not clear what can be inferred about the impact of information frictions on trade. Our study also relates to a broader literature on the importance of imperfect information for the pattern of international trade..$^{4}$ In Rauch and Trindade (2003), improved information allows home firms to rule out more potential foreign trade partners in advance of attempting to form a match. They specifically predict that the Internet will increase the sensitivity of international trade to variable trade costs because improvements in information make cost differences between countries and

\footnotetext{
${ }^{3}$ Some studies question this finding, arguing that it is due to misspecification of the gravity equation (see, e.g., Yotov 2012).

${ }^{4}$ This literature is related to work on the importance of intermediation and networks in determining trade patterns. See Ahn, Khandelwal, and Wei (2011); Antràs and Costinot (2011); and the references therein.
} 
variable trade costs more salient..$^{5}$ Allen (2014) incorporates information frictions in trade model by assuming that heterogeneous producers engage in a costly sequential search process to determine where to sell their produce. His estimates suggest that information frictions are important and help match the observed trading patterns in the data. Dickstein and Morales (2016) show that exporters do not have full information sets and that larger firms possess better knowledge of market conditions in foreign countries. They find that total exports rise, while the number of exporters falls when firms have access to better information. Dasgupta and Mondria (2018) endogenize information in a trade model and show that information costs have nonmonotonic and asymmetric effects on bilateral trade flows.

\section{Data}

Our analysis uses several data sources, which we can link through unique identifiers for each firm and municipality.

\section{A. Firm and Trade Data}

Our firm data come from administrative registers, which are updated annually by Statistics Norway and verified by the Norwegian Tax Authority. The data comprise all nonfinancial joint-stock firms over the period 2000-2008. ${ }^{6}$ We have information from the firm's balance sheets on output (such as revenues) and inputs (such as capital, labor, intermediates) as well as four-digit industry codes and geographical identifiers at the municipality level. We merge the firm dataset with a trade registry assembled from custom records and intra-EU declarations. We have information on the free on board value of all firm-level exports and imports in the period 2000-2008 at the Harmonized System eight-digit nomenclature product category. We merge the product codes with the so-called Rauch classification (see Rauch 1999) that classifies products as homogeneous or differentiated based on whether these products are traded on organized exchanges, have reference prices, or neither.

\section{B. Internet Data}

For the period 2001-2008, we have (i) data on broadband adoption for a stratified random sample of firms and (ii) municipality-level information on availability of broadband Internet to households (independently of whether they take it up). As explained in detail below, we will use the former to measure broadband adoption in firms, while the latter will be used to measure broadband availability

\footnotetext{
${ }^{5}$ Rauch and Trindade (2002) show how the presence of ethnic networks in international trade increases bilateral trade by helping buyers and sellers to match.

${ }^{6}$ Joint-stock firms cover the vast majority of revenues and workers in the private sector. In 2001, for example, they cover 81 percent of revenues and 71 percent of workers.
} 
rates, our instrumental variable. ${ }^{7}$ Throughout the paper, broadband Internet is defined as Internet connections with download speeds that exceed $256 \mathrm{kbit} / \mathrm{s} .{ }^{8}$

Our data on broadband adoptions of firms comes from the annual Community Survey on ICT Usage of Firms, performed by Statistics Norway. This survey includes information on the use of broadband Internet in firms. In each year, the survey samples from the universe of joint-stock firms. The survey design is a stratified random sampling by industry and the number of employees. We calculate municipality-level broadband adoption rates using the joint-stock firms in the Internet survey (20,966 firm-year observations) for which we observe whether or not a firm has adopted broadband Internet. We use sampling weights to produce representative estimates for the corresponding population of joint-stock firms. Online Appendix Figure A.1 displays the distribution of firms by industry. This figure shows the industry composition in our survey sample and in the corresponding population of firms. The two main industries are manufacturing and wholesale/retail. This holds true both in terms of number of firms, trade, number of employees, and total wage bills. We can also see that the distributions in our sample (with sampling weights) closely mirror the distributions for the population of firms. The ability of our sampling weights to produce representative estimates is confirmed in online Appendix Figures A.2 and A.3: the former displays the distributions of output and inputs across firms, while the latter shows the time trends in these variables.

The data on broadband availability come from the Norwegian Ministry of Government Administration. The ministry monitors the supply of broadband Internet to households, and suppliers of broadband to end-users are required to file annual reports about their availability rates to the Norwegian Telecommunications Authority. The availability rates are based on information on the area signal range of the local access points and detailed information on the place of residence of households. In each year and for every municipality, this allows us to measure the fraction of households for which broadband Internet is available, independently of whether they take it up. In computing these availability rates at the municipality level, it is taken into account that multiple suppliers may offer broadband access to households living in the same area, so that double counting is avoided.

\section{Socioeconomic Data}

Most of our socioeconomic data come from administrative registers provided by Statistics Norway. Specifically, we use a longitudinal database that covers every resident from 2000 to 2008. It contains individual demographic information (regarding gender, age, marital status, and number of children), socioeconomic data (educational attainment, income, employment status), and geographic identifiers

\footnotetext{
${ }^{7}$ We do not observe the availability rates of broadband Internet to firms and therefore use the availability rates to households as an instrument for broadband adoption in firms. If the availability of broadband to households were a noisy proxy for the availability to firms, this could generate a weak first stage for our instrument (which we do not have), but it would not be a violation of exclusion or independence conditions.

${ }^{8}$ Before the expansion of broadband Internet, all firms with a telephone connection would have dial-up access to Internet but limited to a bit rate of less than $56 \mathrm{kbit} / \mathrm{s}$. Broadband Internet facilitated Internet use without excessive waiting times.
} 
for municipality of residence. The information on educational attainment is based on annual reports from Norwegian educational establishments, whereas the income data and employment data are collected from tax records and other administrative registers. The household information is from the Central Population Register.

\section{Gravity-Related Data}

We use information on population-weighted bilateral distances between countries from the CEPII as described in Mayer and Zignago (2011). ${ }^{9}$ Information on GDP and Internet usage in foreign countries comes from the World Development Indicator database of the World Bank. Total annual income for Norwegian municipalities is calculated as the total income earned by individuals residing in a given municipality and year. For a subset of countries in our sample, we also have information on English proficiency from the education firm Education First (EF). Aggregating the firm-level trade data to the municipality-country-year level yields a bilateral trade dataset with annual total exports and imports for each Norwegian municipality and foreign country pair. ${ }^{10}$

\section{E. Estimation Sample and Summary Statistics}

Our estimation sample consists of all bilateral pairs between 420 Norwegian municipalities and 181 foreign countries. We create these data by aggregating to the municipality-country-year level international trade conducted by firms in our firm-level dataset, which consists of joint-stock firms with at least five employees. We exclude firms with missing information on capital, intermediate inputs, or location. In the interest of external validity, we also exclude firms that are carrying out extraction of natural resources (including oil and gas). After these restrictions, we have 287,617 firm-year observations.

Table 1 displays summary statistics for the resulting dataset. We observe bilateral trade for about a fifth of all possible municipality-country pairs, and this number is stable throughout the sample. We also divide total trade into homogeneous versus differentiated goods, as suggested by Rauch (1999), and find that the majority of trade is in differentiated goods. We also find that imports are more important than exports in total trade volumes, possibly reflecting the importance of excluded product categories such oil and gas in Norwegian exports.

\footnotetext{
${ }^{9}$ An alternative is to use municipality-specific bilateral distance. This is unlikely to affect our results because it would only make a difference for countries that are very close to Norway. At the same time, municipality distance measures are very sensitive to the location of the central point in Sweden. For example, a municipality in the north of Norway, such as Narvik, is far from the central point of Sweden but is nevertheless very dependent on economic interaction with Sweden thanks to the good infrastructure connecting it to the economy in northern Sweden, such as the municipality of Kiruna. In these cases, it is not obvious how to calculate the distance because it will strongly depend on where one puts the central point. We believe that the most transparent method is to use CEPII's measure of bilateral distances for all Norwegian municipalities.

${ }^{10}$ The information on the trade patterns of Norwegian municipalities thus comes from the knowledge on where firms are located and their trade flows. All variables in the analysis are expressed in thousand 1998 constant US dollars using an NOK/US\$ exchange rate of 7.5.
} 
Table 1-Summary Statistics on Trade (Thousand US\$), Municipality-Country Pairs

\begin{tabular}{lcccc}
\hline \hline & 2001 & 2004 & 2008 & Overall \\
\hline Trade propensity & 0.16 & 0.17 & 0.17 & 0.17 \\
Trade volume & 3,532 & 2,357 & 2,484 & 2,589 \\
Trade Shares & & & \\
$\quad$ Homogeneous goods & 0.18 & 0.16 & 0.14 & 0.16 \\
$\quad$ Differentiated goods & 0.66 & 0.68 & 0.67 & 0.67 \\
$\quad$ Exports & 0.44 & 0.40 & 0.38 & 0.40 \\
$\quad$ Imports & 0.56 & 0.60 & 0.62 & 0.60 \\
Observations (pairs with trade) & 11,462 & 12,096 & 12,429 & 97,646 \\
Observations (pairs with or without trade) & 72,137 & 73,260 & 73,390 & 586,392 \\
\hline
\end{tabular}

Note: Detailed descriptions of the variables are given in online Appendix Table A.1.

\section{Expansion of Broadband Internet}

Over the past decade, many OECD countries were planning the expansion of services related to information and communications technology. In Norway, the key policy change came with the National Broadband Policy, introduced by the Norwegian Parliament in the late 1990s. This section provides details about the program and describes the expansion of broadband Internet. ${ }^{11}$

\section{A. The Program}

The National Broadband Policy had two main goals. The first was to ensure supply of broadband Internet to every area of the country at a uniform price. The second was to ensure that the public sector quickly adopted broadband Internet. The Norwegian government took several steps to reach these goals. First and foremost, it invested heavily in the necessary infrastructure. This investment was largely channeled through the (state-owned) telecom company Telenor, which was the sole supplier of broadband access to end-users in the early 2000s and continues to be the main supplier today. Moreover, virtually all broadband infrastructure was, and still is, owned and operated by Telenor.

Second, local governments were required to ensure supply of broadband Internet by 2005 to local public institutions, such as administrations, schools, and hospitals (St.meld.nr. 49, 2002-2003). To assist municipalities in rural areas, the federal government provided financial support through a funding program known as Høykom. Local governments could receive funds from this program by submitting a project plan that had to be reviewed by a program board with expert evaluations. The stated aim was to ensure broadband availability throughout the country. Once approved, financial support was provided in the initial years of broadband access, thus making it possible for public institutions to cover relatively high initial costs. ${ }^{12}$

\footnotetext{
${ }^{11}$ Our discussion draws on Bhuller et al. (2013) and Akerman, Gaarder, and Mogstad (2015).

${ }^{12}$ During the period 1999-2005, the Høykom program received more than 1,000 such applications and cofunded nearly 400 projects, allocating a total of NOK400 million. From 2002 onward, the Ministry of Education
} 


\section{B. Supply and Demand Factors}

The transmission of broadband signals through fiber-optic cables required installation of local access points. Since 2000, such access points were progressively rolled out, generating considerable spatial and temporal variation in broadband availability. The staged expansion of access points was in part due to limited public funding but also because Norway is a large and sparsely populated country. There are often long driving distances between the populated areas, which are mostly far apart or partitioned by mountains or the fjord-broken shoreline. ${ }^{13}$

The documents describing the National Broadband Policy and the rollout of broadband access points (see St.meld.nr. 38 1997-1998, St.meld.nr. 49 2002-2003) suggest the main supply factors determining the timing of rollout are topographical features and existing infrastructure (such as roads, tunnels, and railway routes) that slow down or speed up physical broadband expansion. ${ }^{14}$ Based on the program accounts, we expect the potential demand factors to be related to public service provision, income level, educational attainment, and the degree of urbanization in the municipality.

\section{Evolution of Broadband Availability}

Figures 1 and 2 show the variation in our measure of broadband availability to households over time and across municipalities. By 2000, broadband transmission centrals were installed in the cities of Oslo, Stavanger, and Trondheim as well as in a few neighboring municipalities of Oslo and Trondheim. However, because of limited area signal range, broadband Internet was available for less than one-third of the households in each of these municipalities. More generally, the figures illustrate that for a large number of municipalities, there was no broadband availability in the first few years, whereas most municipalities had achieved fairly high availability rates in 2005. Moreover, there is considerable variation in availability rates within the municipalities in these years. Indeed, few municipalities experience a complete shift from no availability to full availability in a given year; rather, access points were progressively rolled out within and across municipalities, generating a continuous measure of availability rates that display considerable temporal and spatial variation (even conditional on year and municipality fixed effects).

and Research cofinanced another scheme (Høykom skole), providing financial support for broadband infrastructure in public schools. There are virtually no private schools in Norway.

${ }^{13}$ The Norwegian territory covers about 149,400 square miles, an area about the size of California or Germany, with around 13 percent and 6 percent of those regions' populations (in 2008), respectively. The country is dominated by mountainous or high terrain as well as a rugged coastline stretching about 1,650 miles, broken by numerous fjords and thousands of islands.

${ }^{14}$ The reason is that the transmission of broadband signals through fiber-optic cables required installation of local access points. In areas with challenging topography and landscapes, it was more difficult and expensive to install the local access points and the fiber-optic cables. Furthermore, the existing infrastructure mattered for the marginal costs of installing cables to extend the availability of broadband within a municipality and to neighboring areas. 

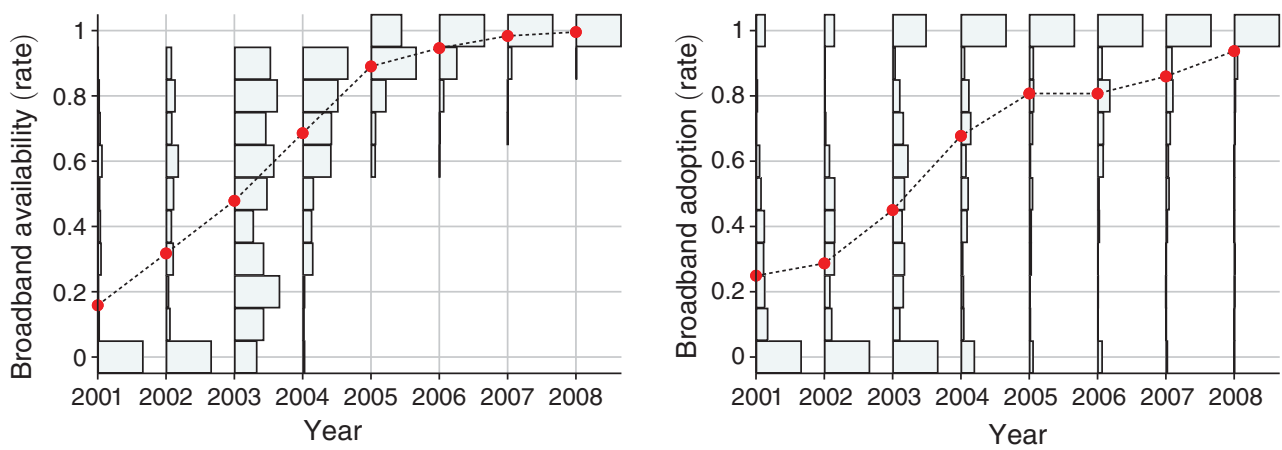

Figure 1. Availability and Adoption of Broadband Internet across Municipalities and Time

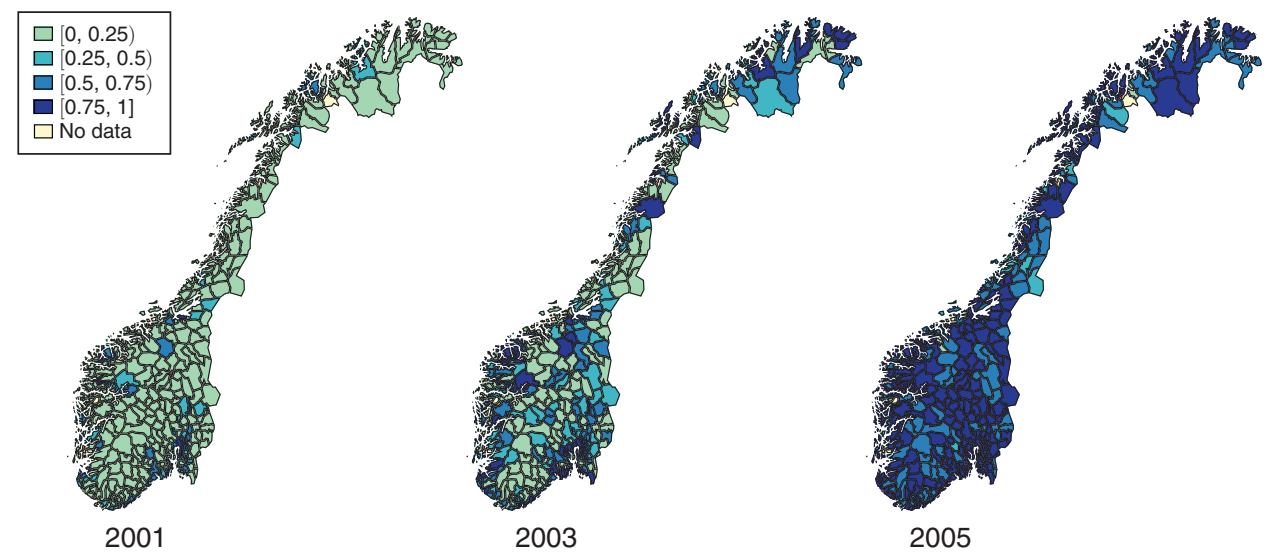

Figure 2. Geographical Distribution of Broadband Availability Rates

\section{Broadband Adoption in Firms}

Before turning to the estimation of the augmented gravity model in the next section, it is useful to understand the pattern of broadband adoption in firms. Figure 3 illustrates our identification strategy by drawing a scatterplot of the broadband adoption rate of firms against the broadband availability rate in the municipality, after taking out municipality and year fixed effects. The figure is based on the following regression that uses the sample of firms for which we observe whether or not a firm has adopted broadband Internet:

$$
d_{i m t}=\delta z_{m t}+\gamma_{m}+\eta_{t}+\nu_{i m t},
$$

where $d_{i m t}$ equals one if firm $i$ in municipality $m$ in year $t$ had adopted broadband Internet and is zero otherwise. Our instrument $z_{m t}$ is the broadband coverage rate in municipality $m$ in year $t$ (i.e., the share of households for which broadband Internet is available, independently of whether they take it up). To exploit the 


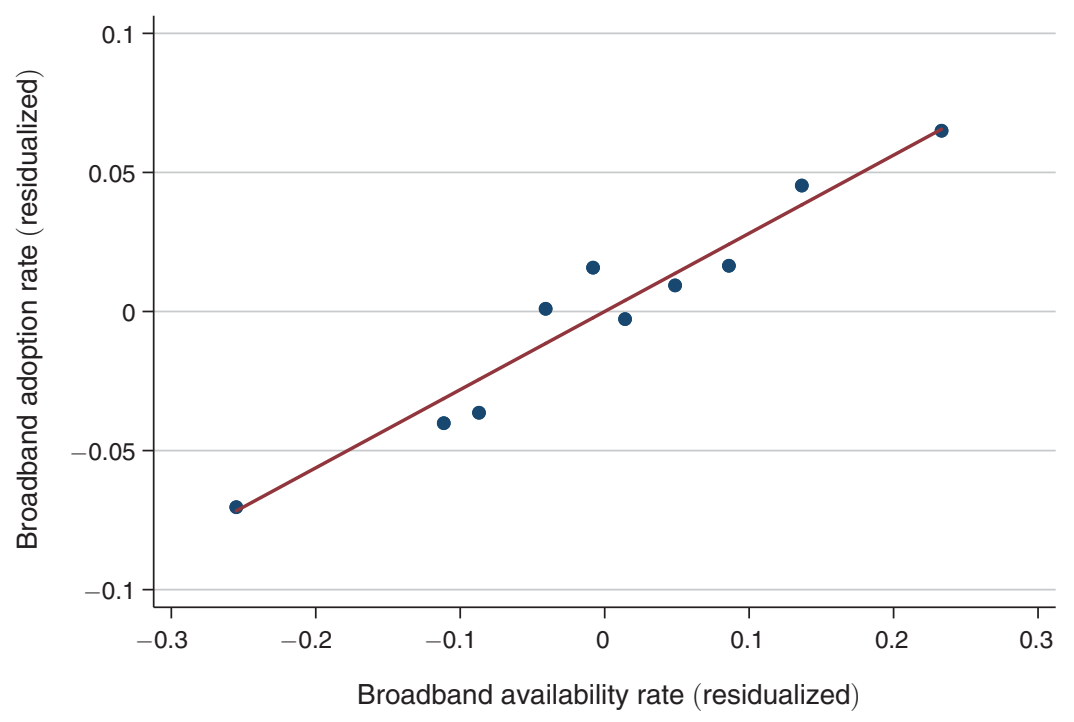

Figure 3. First-Stage Regression

Notes: The scatterplot shows average (residual) adoption at (residual) availability deciles. The estimated slope equals $0.28(0.02)$.

quasi-randomization provided by the broadband Internet rollout documented above, we need to condition on municipality fixed effects $\gamma_{m}$ and time dummies $\eta_{t}$.

Figure 3 shows a strong linear association between broadband availability and adoption rates. The $y$-axis reports residuals from a regression of broadband adoption rates of firms on municipality and year fixed effects. The $\mathrm{x}$-axis reports residuals from a regression of broadband availability rates of households on municipality and year fixed effects. We estimate the coefficient on the availability rate $\delta$ to be about 0.28 with a standard error of 0.02 . This estimate implies that a 10 percentage point increase in broadband availability induces (an additional) 2.8 percent of the firms to adopt broadband Internet.

To understand what type of firms quickly adopt broadband when it becomes available (i.e., the compliers to the instrument), we partition the sample of firms with observed technology into eight mutually exclusive groups by industry (the four largest industries) and share of workers with college degree (above and below median within each industry). We then allow the coefficient $\delta$ to vary across these groups. Column 1 of Table 2 displays the size of the sample in each industry-skill group. The estimates of $\delta$ for the different types of firms are shown in the second column of Table 2 . The proportion of the compliers of a given type is then calculated as the ratio of $\hat{\delta}$ for that subgroup to the $\hat{\delta}$ in the overall sample, multiplied by the proportion of the sample in the industry-skill group reported in column 3. Column 4 shows the distribution of the compliers by industry and skill intensity. We see that firms with a large share of high-skilled workers are overrepresented among the compliers in every industry as compared to the sample of firms at large.

Columns 5-9 of Table 2 report the characteristics of each industry-skill group. Columns 5 and 6 show that in every industry the complier firms tend to be relatively 
TABle 2-Characterizing COMPLier Firms (by sector and skill endowment of workers)

\begin{tabular}{|c|c|c|c|c|c|c|c|c|c|}
\hline & \multirow[b]{2}{*}{$\begin{array}{c}\text { Observations } \\
\text { (1) }\end{array}$} & \multirow[b]{2}{*}{$\begin{array}{c}\hat{\delta} \\
(2)\end{array}$} & \multicolumn{2}{|c|}{ Composition } & \multirow{2}{*}{$\begin{array}{c}\text { log labor } \\
\text { productivity } \\
(5)\end{array}$} & \multirow{2}{*}{$\begin{array}{c}\text { Number } \\
\text { of } \\
\text { workers } \\
(6)\end{array}$} & \multirow{2}{*}{$\begin{array}{c}\text { Share of } \\
\text { workers } \\
\text { using PC } \\
(7)\end{array}$} & \multicolumn{2}{|c|}{ Trade } \\
\hline & & & $\begin{array}{c}\text { Sample } \\
(3)\end{array}$ & $\begin{array}{c}\text { Compliers } \\
\text { (4) }\end{array}$ & & & & $\begin{array}{c}\text { Propensity } \\
\text { (8) }\end{array}$ & $\begin{array}{l}\text { Volume } \\
\text { (9) }\end{array}$ \\
\hline $\begin{array}{l}\text { Constructi } \\
<\text { median }\end{array}$ & 1,571 & $0.37(0.06)$ & 0.07 & 0.11 & 4.7 & 19.0 & 0.25 & 0.29 & 29 \\
\hline$>$ median & 1,571 & $0.47(0.05)$ & 0.07 & 0.14 & 4.8 & 41.0 & 0.37 & 0.31 & 280 \\
\hline $\begin{array}{l}\text { Manufactu } \\
<\text { median }\end{array}$ & 2,330 & $0.19(0.04)$ & 0.11 & 0.08 & 4.7 & 43.6 & 0.34 & 0.78 & 2,517 \\
\hline$>$ median & 2,331 & $0.26(0.04)$ & 0.11 & 0.12 & 5.0 & 78.5 & 0.60 & 0.82 & 11,805 \\
\hline $\begin{array}{l}\text { Service } \\
<\text { median }\end{array}$ & 2,187 & $0.15(0.07)$ & 0.10 & 0.06 & 4.4 & 51.3 & 0.46 & 0.28 & 139 \\
\hline$>$ median & 2,187 & $0.22(0.07)$ & 0.10 & 0.09 & 4.7 & 31.3 & 0.93 & 0.44 & 522 \\
\hline $\begin{array}{l}\text { Wholesale } \\
<\text { median }\end{array}$ & retail & $0.20(0.04)$ & 0.16 & 0.13 & 5.1 & 18.5 & 0.44 & 0.52 & 515 \\
\hline$>$ median & 3,415 & $0.25(0.04)$ & 0.16 & 0.17 & 5.4 & 30.3 & 0.68 & 0.70 & 3,859 \\
\hline Overall & 20,954 & $0.25(0.04)$ & 1.00 & 1.00 & 4.9 & 35.0 & 0.50 & 0.52 & 2,098 \\
\hline
\end{tabular}

Notes: We partition the survey sample of joint-stock firms into eight mutually exclusive groups by industry (four largest industries and others) and skill intensity (above and below median within each industry). Column 1 displays the proportion of the sample in each industry-skill intensity group. Column 2 reports estimates of $\delta$ from equation (1) for each group. The proportion of the compliers of a given type is then calculated as the ratio of $\hat{\delta}$ for that subgroup to the $\hat{\delta}$ in the overall sample, multiplied by the proportion of the sample in the industry-skill group. Column 4 shows the distribution of the compliers by industry and skill intensity. Columns 5-9 report baseline characteristics of each industry-skill group. Sampling weights are used to ensure representative results for the population of joint-stock firms.

productive and large (as measured by labor productivity and employment), column 7 shows that computer use is higher in complier firms, and columns 8 and 9 show that they are more likely to trade internationally at both the extensive and intensive margins. These findings illustrate that when broadband Internet becomes available, it is not randomly adopted; instead, it is more quickly adopted in firms in which complementary factors are abundant, including computers and skilled workers. This is consistent with the predictions of a model of endogenous technology adoption where firms' choices reflect principles of comparative advantage (see, e.g., Beaudry and Green 2003; Beaudry and Green 2005; Beaudry, Doms, and Lewis 2010).

\section{Empirical Model and Identification}

In this section, we specify a gravity equation augmented with interaction terms between broadband adoption and covariates and outline our estimation approach. The main challenge in the estimation is to address the potential endogeneity of broadband adoption. Randomizing broadband adoption is not feasible: we cannot in practice force firms to adopt a new technology. One can, however, think of a field experiment that randomizes broadband availability at the municipality level. The randomization would break the correlation between availability rates and unobserved determinants of trade. The intention of our identification strategy is to mimic this hypothetical experiment. Our source of exogenous variation comes from the staged 
installation of broadband infrastructure, which generated spatial and temporal variation in broadband availability and, consequently, adoption as documented above.

\section{A. Broadband Adoption and Trade}

Most contemporaneous estimates of the gravity model depart from models that deliver the following structure:

$$
X_{i j}=b_{0}\left(\frac{Y_{i}}{\Omega_{i}}\right)^{b_{I}}\left(\frac{Y_{j}}{\Phi_{j}}\right)^{b_{J}} \tau_{i j}^{b_{\tau}},
$$

where $X_{i j}$ is trade between region $i$ and region $j, Y_{i}$ is GDP in origin $i, Y_{j}$ is GDP in destination $j, \Omega_{i}$ and $\Phi_{j}$ are the multilateral trade resistance terms, and finally $\tau_{i j}$ is a measure of bilateral trade costs such as distance. To investigate how Internet affected trade, we extend this core setup by letting the elasticity $b_{\tau}$ as well as $b_{I}, b_{J}$, and $b_{0}$ depend on broadband Internet use in $i, d_{i}$, i.e.,

$$
b_{k}=\alpha_{k}+\beta_{k} d_{i}, \quad k \in\{0, I, J, \tau\} .
$$

Then, we log-linearize and parameterize (2) and let it depend on time $t$, giving the following augmented gravity equation:

$$
\begin{aligned}
\log X_{i j t}= & \left(\alpha_{0}+\beta_{0} d_{i t}\right)+\left(\alpha_{I}+\beta_{I} d_{i t}\right) \log Y_{i t}+\left(\alpha_{J}+\beta_{J} d_{i t}\right) \log Y_{j t} \\
& +\left(\alpha_{\tau}+\beta_{\tau} d_{i t}\right) \log \tau_{\text {Norway }, j}+\gamma_{i j}+\tau_{t}+\varepsilon_{i j t},
\end{aligned}
$$

which can be written more compactly as

$$
\log X_{i j t}=w_{i j t}^{\prime}\left(\alpha+\beta d_{i t}\right)+\gamma_{i j}+\tau_{t}+\varepsilon_{i j t}
$$

with

$$
w_{i j t}^{\prime}=\left(\begin{array}{lll}
1 & \log Y_{i t} & \log Y_{j t} \log \tau_{\text {Norway }, j}
\end{array}\right)
$$

and where subscript $i$ refers to municipality, subscript $j$ to destination/source country, and subscript $t$ to year. The outcome $X_{i j t}$ is total trade between $i$ and $j$ (exports from municipality $i$ to country $j+$ imports from country $j$ to municipality $i) ; d_{i t}$ is the broadband adoption rate (the fraction of firms that have adopted broadband Internet). The vector $w_{i j t}$ contains $Y_{i t}$ the economic size of origin $i$ (as measured by municipality $i$ 's total income), $Y_{j t}$ the economic size of destination $j$ (as measured by country $j$ 's GDP), and $\tau_{\text {Norway }, j}$ the distance between Norway and $j$. Because $w_{i j t}$ also includes a constant term, we allow broadband use to directly affect trade between $i$ and $j$ through a change in the intercept. We furthermore normalize the variables in $w_{i j t}$ to mean zero so that we can interpret the coefficient on the main effect of broadband use as the average effect in the sample. The coefficients $\alpha=\left(\alpha_{0} \alpha_{I} \alpha_{J} \alpha_{\tau}\right)^{\prime}$ are the intercept and the coefficients on the standard gravity 
terms, while the coefficients $\beta=\left(\beta_{0} \beta_{I} \beta_{J} \beta_{\tau}\right)^{\prime}$ correspond to the main effect of broadband use and heterogeneity in its impact depending on distance and size.

We are primarily interested in the vector of coefficients $\beta$, which captures the direct effect of broadband Internet $\beta_{0}$ and the heterogeneity in its impact depending on distance $\beta_{\tau}$ as well as the economic size of the origin municipality $\beta_{I}$ and destination country $\beta_{J}$. If broadband Internet $d_{i t}$ was randomly adopted, then OLS estimates of equation (3) would allow us to draw causal inference about the coefficients $\beta$. However, the OLS estimates are likely to suffer from biases due to correlated unobservables and reverse causation. To address these concerns, we will instrument the fraction of firms that have adopted broadband Internet in municipality $i$ in year $t\left(d_{i t}\right)$, with the broadband coverage rate in municipality $i$ at the end of year $t\left(z_{i t}\right)$. This gives the following first-stage equations:

$$
\begin{array}{r}
d_{i t}=w_{i j t}^{\prime}\left(\delta_{0}+\phi_{0} z_{i t}\right)+\varsigma_{0, i j}+\theta_{0, t}+\nu_{0, i j t}, \\
d_{i t} \log \tau_{\text {Norway }, j}=w_{i j t}^{\prime}\left(\delta_{\tau}+\phi_{\tau} z_{i t}\right)+\varsigma_{\tau, i j}+\theta_{\tau, t}+\nu_{\tau, i j t}, \\
d_{i t} \log Y_{i t}=w_{i j t}^{\prime}\left(\delta_{s}+\phi_{s} z_{i t}\right)+\varsigma_{s, i j}+\theta_{s, t}+\nu_{s, i j t}, \\
d_{i t} \log Y_{j t}=w_{i j t}^{\prime}\left(\delta_{d}+\phi_{d} z_{i t}\right)+\varsigma_{d, i j}+\theta_{d, t}+\nu_{d, i j t} .
\end{array}
$$

The system is exactly identified without functional form assumptions. We have as many excluded variables $\left(z_{i t}\right.$ and its interaction with the three covariates in $\left.w_{i j t}\right)$ as the number of included endogenous variables $\left(d_{i t}\right.$ and its interaction with the three covariates in $\left.w_{i j t}\right)$. Economically, equation (4) captures the main effect of $d_{i t}$, while equations (5)-(7) represent interaction effects. Importantly, we allow the effects of both $d_{i t}$ and $z_{i t}$ to vary with the same set of covariates in the same way, and, thus, we do not rely on functional form assumptions to recover the parameters of interest (the vector of coefficients $\beta$ ).

The IV approach we use isolates the exogenous variation in Internet adoption that comes from the staged installation of broadband infrastructure that we described in Section II. Given that we control for municipality-country fixed effects $\gamma_{i j}$ and calendar time fixed effects $\tau_{t}$, the identification is similar in spirit to a difference-in-difference design. The key threat to identification is therefore that the timing of the broadband rollout might be related to different underlying trends in the trade patterns across municipality-country pairs. It is therefore reassuring that the timing does not appear to be systematically related to key observable correlates of trade. Nevertheless, after presenting the main results, we challenge our identification strategy in a number of ways, which show that our findings are robust across a variety of specifications and samples. In particular, we add both municipality-specific and destination-specific linear trends, and we include a full set of municipality-year fixed effects. While we lose some precision as expected, the main results do not materially change.

It would be useful to also obtain reliable estimates of the main effects of the gravity terms $\alpha$ to interpret the size of the coefficients $\beta$. However, since $\gamma_{i j}$ absorbs all determinants of trade that are fixed at the municipality-country-pair level, including distance, our main specification does not allow us to draw inference about the 
direct effect of distance on trade $\alpha_{\tau}$. We therefore also report estimates from a specification that replaces the municipality-country-pair fixed effects $\gamma_{i j}$ with municipality fixed effects. It is important to observe, however, that the estimates of $\alpha$ must be interpreted with caution, as there are several sources of bias that may not necessarily be properly accounted for. 15

\section{B. Regression Model of Intention-to-Treat Effects}

IV estimation of equation (3) requires that increased availability of broadband Internet affects trade only through broadband adoption in firms and not directly in any other way. This exclusion restriction could be questioned. For example, one may be worried that increased availability of broadband Internet among households changes their demand for goods. Since Norway is a small open economy, one would expect this effect to be relatively small, at least for firms in the tradable sector where demand is given by the world market. However, we cannot rule out that the exclusion restriction is violated. Thus, we also present estimates of the reduced-form effects of (increasing) broadband coverage rates $z_{i t}$ on trade-so-called intention-to-treat effects-which do not rely on this exclusion restriction but only require exogeneity of the instrument $z_{i t}$.

To estimate these intention-to-treat effects of the increased availability of broadband Internet, we specify the following panel data regression:

$$
\log X_{i j t}=w_{i j t}^{\prime}\left(\varphi+\eta z_{i t}\right)+\gamma_{i j}+\tau_{t}+u_{i j t}
$$

Equation (8) is the gravity equation augmented with interaction terms between broadband availability and the covariates $w_{i j t}$. The coefficients $\varphi=\left(\varphi_{0} \varphi_{I} \varphi_{J} \varphi_{\tau}\right)^{\prime}$ estimate the relationship between $(\log )$ trade and locations with different distance and economic sizes before the rollout of broadband Internet $\left(z_{i t}=0\right)$, while the coefficients of primary interest $\eta=\left(\eta_{0} \eta_{I} \eta_{J} \eta_{\tau}\right)^{\prime}$ measure the interaction effects between these covariates and broadband availability. As above, because of the normalization of the variables in $w_{i j t}$, we can interpret the coefficient on the main effect of broadband availability as the average effect in the sample.

\section{Inference and Estimation}

While we can estimate equation (8) on the full estimation sample of municipality-country pairs, we rely on information on broadband adoption from surveys to estimate equations (4)-(7). This means that we estimate the first stages in a subsample of the full estimation sample of municipality-country pairs that we use in the reduced form. It is well known that in such cases we need to adjust the estimated standard errors (Angrist and Krueger 1995, Inoue and Solon 2010). To do this, however, we cannot use existing results. This is because our first stages are

\footnotetext{
${ }^{15}$ See Baldwin and Taglioni (2006) for a discussion of the challenges to consistent estimation of the coefficients in the gravity equation.
} 
estimated in a subsample of the full sample used in the reduced-form estimation and not in a separate (split) sample as in existing work.

If we generically write the second stage as

$$
y=X \beta+e
$$

with first stages

$$
X=Z \Pi+U
$$

and corresponding reduced form

$$
y=Z \gamma+v
$$

where $\gamma=\Pi \beta$ and $v=U \beta+e$, then we show in online Appendix B that

and

$$
d \beta / d \text { vec } \Pi=-\left(\beta^{\prime} \otimes\left(\Pi^{\prime} Z^{\prime} Z \Pi\right)^{-1} \Pi^{\prime} Z^{\prime} Z\right)
$$

$$
d \beta / d \gamma=\left(\Pi^{\prime} Z^{\prime} Z \Pi\right)^{-1} \Pi^{\prime} Z^{\prime} Z
$$

Let $\eta=\left(\operatorname{vec} \Pi^{\prime} \gamma^{\prime}\right)^{\prime}$, then these results can then be used to construct the covariance matrix of $\beta$ using the Delta method as follows:

$$
V(\beta)=(\partial \beta / \partial \eta)^{\prime} V(\eta)(\partial \beta / \partial \eta)
$$

where

$$
\operatorname{var}(\eta)=\left(I_{K+1} \otimes E\left[Z^{\prime} Z\right]^{-1}\right) E\left[Z^{\prime} \xi \xi^{\prime} Z\right]\left(I_{K+1} \otimes E\left[Z^{\prime} Z\right]^{-1}\right)
$$

and $\xi=\left(\operatorname{vec} U^{\prime} v^{\prime}\right)^{\prime}$. In a first step, we directly get the covariance matrices of $\hat{\Pi}_{k}$ and $\hat{\gamma}$ from our OLS estimation. These are then used to compute residuals $\hat{\xi}$. An estimate of $E\left[Z^{\prime} \xi \xi^{\prime} Z\right]$ is obtained using $\hat{\xi}$ and standard covariance matrix estimation using the method of moments, allowing for clustering at the municipality level.

\section{Assessing the Identification Strategy}

Broadband coverage, the instrumental variable $z_{i t}$ in our 2SLS estimation above, varies across municipalities and time. Given that we are controlling for fixed effects for municipality-country-pairs and years, the core of our design is similar in spirit to a difference-in-difference setup at the municipality-country level. The key threat to identification of how broadband affects the relationship between trade and distance is therefore that the timing of the broadband rollout might be related to different underlying trends in this relationship across municipality-country pairs. Before turning to a more detailed regression-based analysis that addresses this concern, we examine here the determinants of the timing of the broadband rollout. 


\section{E. Timing of the Broadband Rollout}

Our identification strategy controls for municipality-country pair and year fixed effects. This is motivated by two features of the program that expanded broadband availability. First, most of the confounding supply and demand factors tend to vary little over time and are therefore accounted for by the municipality-country fixed effects. Second, the timing of the rollout (i.e., the variation in broadband availability conditional on the fixed effects) is unlikely to covary with key correlates of trade.

To investigate whether the data are consistent with these program features, we first regress $z_{i t}$ on municipality and time fixed effects as well as time-varying supply and demand factors. We find that 79 percent of the variation in broadband availability can be attributed to time-invariant municipality characteristics and common time effects, while less than 3 percent of the variation in broadband availability can be attributed to a large set of time-varying variables. ${ }^{16}$

To further examine the relationship between the timing of broadband rollout and baseline (2000) municipality characteristics $m_{i, t 0}$, we estimate the following equation:

$$
\Delta z_{i t}=\eta_{t}+\theta_{t} m_{i, t 0}+\epsilon_{i j t}
$$

where $\Delta z_{i t}=z_{i t}-z_{i, t-1}$ is the change in the broadband availability rate and $\eta_{t}$ is a vector of year fixed effects. To match the IV and reduced-form model, we use weights so that the sample is representative with respect to municipality-country pairs. We estimate regressions where we let $m_{i, t 0}$ contain municipality-level information from year 2000 on demography, average levels of international trade, inputs and output, industry structure, and pre-reform growth rates in trade. Demographic variables include size of population, share of population residing in a densely populated locality (an urbanization indicator), income level, and education. For firm inputs and output, we have included municipality averages of revenues, intermediates, capital stock, number of workers, and wage bill. As measures of industry structure, we use number of firms, employment share in manufacturing, employment share in wholesale, and baseline (1999-2000) trade growth. Finally, we also look at the fraction of firms in the municipality that import and export, as well as the mean value of imports and exports in the municipality.

Online Appendix Figure A.4 plots the estimated coefficients $\theta_{t}$ (and the associated 95 percent confidence intervals) from the multivariate regression model in equation (9). We have standardized both the dependent variable and $m_{i, t 0}$ so that we can interpret $\theta_{t}$ as correlation coefficients. The main pattern that stands out is that broadband was rolled out in more urban areas at the start of the rollout. There are some other correlations with rollout and municipality characteristics, especially in the earlier years. Figure A.4 also plots estimates of $\theta_{t}$ from regressions where $m_{i, t 0}$

\footnotetext{
${ }^{16}$ The time-varying variables include demographic factors (income level, education, share of population residing in a densely populated locality, size of population), inputs and output (municipality averages of revenues, intermediates, capital stock, number of workers, and wage bill), industry structure (employment share in manufacturing, employment share in wholesale, and employment share in transport), and the fraction of firms in the municipality that import and export, as well as the mean value of imports and exports in the municipality.
} 
only contain one municipality-level variable in addition to a control for urbanization. These estimates confirm that urban areas is the key predictor of Internet arrived earlier. From 2003 and onward, there appears to be little if any systematic relationship between the timing of the broadband expansion and the other municipality characteristics.

Taken together, the evidence presented in online Appendix Figure A.4 suggests that, apart from the degree of urbanization, the rollout of broadband availability does not appear to be systematically related to key observable correlates of trade. Nevertheless, a concern is that there could be differential underlying trends in the outcomes of interest depending on urbanization or some characteristic. To examine whether our estimates are biased because of differential trends, we perform three robustness checks. First, we make sure that our estimates are robust to excluding the three or five biggest cities. Second, we explicitly allow for differential trends by initial conditions as measured in year 2000. This is done by interacting urbanization and other municipality-level information with municipality-specific time trends. Third, we show robustness to allowing for differential time trends across areas by including municipality- and destination-specific time trends. To check that the estimated effects are not driven by time-varying observable factors, we additionally report results with and without a large set of time-varying controls for the potential supply and demand factors (discussed in Section II).

\section{Internet and the Relationship between Distance and Trade}

\section{A. Main Results}

Table 3 reports our estimates of a basic gravity equation, and the augmented gravity equation in (3), as well as the (intention-to-treat) effects of broadband coverage on trade from (8). The sample consists of all municipality-country-year combinations where one trading partner is a Norwegian municipality and the other a country (not Norway) and where the value of trade is positive.

\section{B. OLS Estimates}

The first three columns show the estimation results using OLS. Column 1 shows the estimates from the gravity equation that do not include any interactions with Internet. To estimate the coefficient on log distance, we do not include the pair-specific fixed effects $\gamma_{i j}$ and only use municipality and time fixed effects. We see that the magnitude of the elasticity of trade with respect to distance is 1.25 , and the elasticities with respect to economic size are 0.50 for the origin (municipality) and 0.74 for the destination (foreign country). While the origin elasticity is quite imprecisely estimated, we find that the gravity-related elasticities in our dataset lie well within the range commonly found in the literature (see, for example, table 3.4 of Head and Mayer 2014).

In column 2, we report the OLS estimates of equation (3), which include the interaction variables for Internet adoption and the gravity variables. As in column 1, in order to estimate an effect on distance, we include municipality and time fixed 
Table 3-Gravity Estimation Results-Trade Volume $(\log )$

\begin{tabular}{|c|c|c|c|c|c|}
\hline & \multicolumn{3}{|c|}{ OLS } & \multirow{2}{*}{$\begin{array}{l}\text { ITT } \\
(4)\end{array}$} & \multirow{2}{*}{$\begin{array}{l}\text { SSIV } \\
(5)\end{array}$} \\
\hline & (1) & (2) & (3) & & \\
\hline $\log \tau_{N O R, j t}$ & $\begin{array}{r}-1.253 \\
(0.023)\end{array}$ & $\begin{array}{c}-1.208 \\
(0.032)\end{array}$ & & & \\
\hline $\log Y_{i t}$ & $\begin{array}{c}0.499 \\
(0.275)\end{array}$ & $\begin{array}{c}0.702 \\
(0.303)\end{array}$ & $\begin{array}{c}0.880 \\
(0.378)\end{array}$ & $\begin{array}{c}0.709 \\
(0.348)\end{array}$ & $\begin{array}{c}0.675 \\
(0.326)\end{array}$ \\
\hline $\log Y_{j t}$ & $\begin{array}{c}0.736 \\
(0.022)\end{array}$ & $\begin{array}{c}0.721 \\
(0.021)\end{array}$ & $\begin{array}{c}1.552 \\
(0.167)\end{array}$ & $\begin{array}{c}1.668 \\
(0.165)\end{array}$ & $\begin{array}{c}1.734 \\
(0.152)\end{array}$ \\
\hline$d_{i t}$ & & $\begin{array}{c}0.046 \\
(0.047)\end{array}$ & $\begin{array}{c}0.063 \\
(0.051)\end{array}$ & & $\begin{array}{c}0.252 \\
(0.489)\end{array}$ \\
\hline$d_{i t} \times \log \tau_{N O R, j t}$ & & $\begin{array}{r}-0.092 \\
(0.030)\end{array}$ & $\begin{array}{r}-0.093 \\
(0.028)\end{array}$ & & $\begin{array}{r}-0.171 \\
(0.045)\end{array}$ \\
\hline$d_{i t} \times \log Y_{i t}$ & & $\begin{array}{r}-0.006 \\
(0.048)\end{array}$ & $\begin{array}{r}-0.031 \\
(0.053)\end{array}$ & & $\begin{array}{c}0.088 \\
(0.081)\end{array}$ \\
\hline$d_{i t} \times \log Y_{j t}$ & & $\begin{array}{c}0.075 \\
(0.019)\end{array}$ & $\begin{array}{c}0.037 \\
(0.014)\end{array}$ & & $\begin{array}{c}0.094 \\
(0.022)\end{array}$ \\
\hline$z_{i t}$ & & & & $\begin{array}{c}0.050 \\
(0.105)\end{array}$ & \\
\hline$z_{i t} \times \log \left(\tau_{N O R, j t}\right)$ & & & & $\begin{array}{r}-0.119 \\
(0.035)\end{array}$ & \\
\hline$z_{i t} \times \log Y_{i t}$ & & & & $\begin{array}{c}0.050 \\
(0.050)\end{array}$ & \\
\hline$z_{i t} \times \log Y_{j t}$ & & & & $\begin{array}{c}0.064 \\
(0.017)\end{array}$ & \\
\hline Mean dependant variable & 10.96 & 11.07 & 11.07 & 10.96 & 10.96 \\
\hline Observations & 97,646 & 89,522 & 89,522 & 97,646 & 97,646 \\
\hline Pair fixed effects & & & $\checkmark$ & $\checkmark$ & $\checkmark$ \\
\hline
\end{tabular}

Notes: $\tau=$ bilateral distance, $Y=$ economic size, $d=$ broadband adoption rate, $z=$ broadband coverage rate. Subscript $i$ refers to municipality, $j$ to destination/source country, and $t$ to year. Columns 1 and 2 include fixed effects for year and municipality. Columns 3 to 5 include fixed effects for year and municipality-country-specific pairs. The sample period is 2001-2008. The sample consists of all municipality-country-year combinations where one trading partner is a Norwegian municipality and the other a country (not Norway) and where log value of trade is positive. All reported standard errors are clustered at the municipality level.

effects but not pair-specific fixed effects. As explained above, all main gravity variables are expressed as deviations from population means. This means that we can interpret the main elasticities as the elasticities without Internet, and the coefficient on the interactions between Internet and the intercept as the partial effect of Internet at the sample average. The main gravity coefficients do not change significantly. As to the Internet-related terms, we find a positive but imprecisely estimated main effect of Internet adoption on trade. However, we find a negative and statistically significant effect of the interaction variable with distance, which means that the elasticity of trade with respect to distance increases in magnitude with Internet. Moreover, the elasticity with respect to destination market size, $Y_{j t}$, increases significantly. We do not find evidence that the elasticity with respect to origin market size depends on Internet adoption. 
In column 3, we present our baseline specification where we include also the pair-specific fixed effects as specified in equation (3), which capture all time-constant heterogeneity across all bilateral pairs. In this specification, the coefficients are estimated using variation within pairs and across time. The signs and magnitudes of the interaction coefficients with Internet take-up do not change significantly when adding these controls.

\section{Reduced-Form Effects}

The OLS estimates in column 3 suggest that adoption of broadband Internet makes trade patterns more sensitive to distance and the size of the destination market. However, an important concern with the OLS results is that potential endogeneity of Internet take-up biases these estimates. In the remainder, we will therefore use the rollout of broadband Internet coverage as an instrument for Internet take-up.

Before turning to our 2SLS estimates, we will first discuss the reduced-form effects of broadband Internet rollout. These intention-to-treat results, which do not rely on exclusion restrictions, are illustrated in Figure 4. For brevity, we focus on one key parameter in equation (8), the coefficient $\eta_{I}$ on the interaction term between broadband availability and distance. The goal of the figure is to show how changes in broadband availability covary with changes in the relationship between trade and distance.

The way we construct this figure is that we take for each municipality the year in which the availability of Internet expanded the most. We denote this year as $\bar{t}_{m}$. We keep all municipalities with observations at least two years before $\left(\bar{t}_{m}-2\right.$ and $\left.\bar{t}_{m}-1\right)$ and two years after $\left(\bar{t}_{m}\right.$ and $\left.\bar{t}_{m}+1\right)$ to construct a balanced sample. We then run a basic gravity regression where we interact the gravity variables with dummies indicating year $s$ relative to the year of maximum expansion $\bar{t}_{m}$. To be specific, we conduct the following regression:

$$
\log X_{i j t}=w_{i j t}^{\prime} \sum_{s=-2}^{1} \eta_{s}\left\{\begin{array}{ll}
1 & \text { if } t-\bar{t}_{m}=s \\
0 & \text { otherwise }
\end{array}\right\}+\gamma_{i t}+u_{i j t} .
$$

This traces how the coefficients on all gravity variables vary relative to the year of the maximum expansion. We plot the result in Figure 4. The magnitude of the distance elasticity (plotted here in absolute terms) follows the expansion of Internet availability fairly closely. The largest increase in the distance elasticity takes place at the same time as the expansion of Internet availability.

In column 4 of Table 3, we report the regression estimates of intention-to-treat effects of broadband coverage on trade from (8). These estimates show that going from no coverage to full coverage increases the magnitude of the elasticity of trade with respect to distance by 0.12 and the elasticity of trade with respect to destination size by 0.06 . For distance, this means that an increase in Internet availability of 10 percentage points increases trade for a country at the twenty-fifth distance percentile by 1.1 percent more than for a country at the seventy-fifth distance percentile. The same difference for the size (GDP) of a destination is 2.1 percent. There is no evidence that broadband coverage impacts the elasticity of trade with 


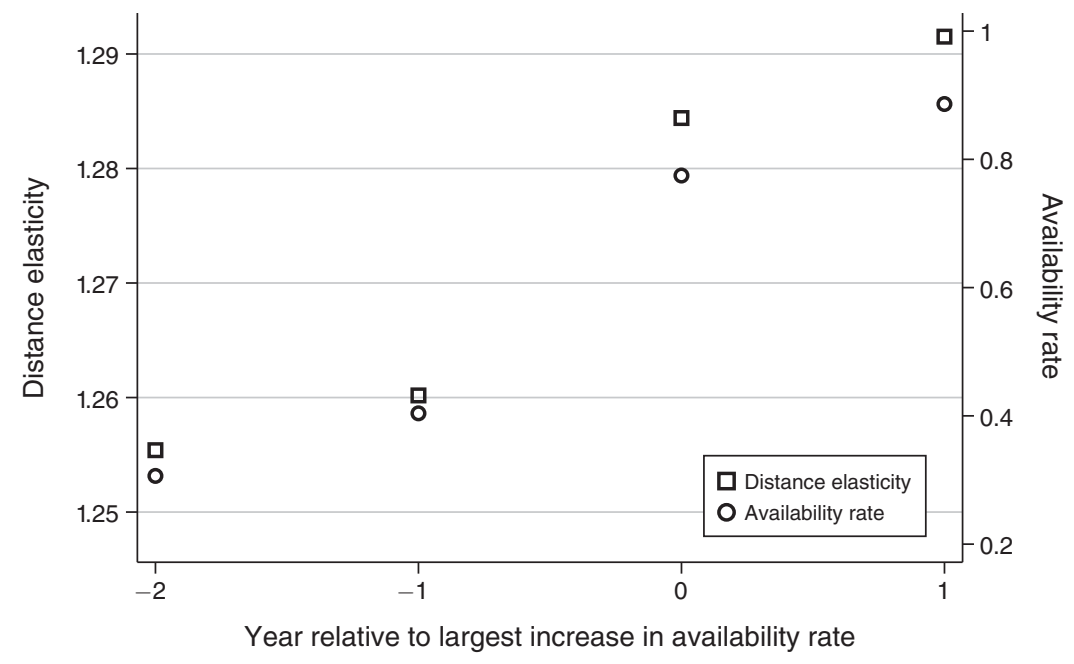

Figure 4. Graphical Illustration of How Changes in Broadband Availability Covary with Changes in THE Distance Elasticity

Notes: This figure presents the estimates from equation (10). The sample period we consider is 2001-2008. The sample consists of all municipality-country-year combinations where one trading partner is a Norwegian municipality and the other a country (not Norway) and where log value of trade is positive. All reported standard errors are clustered at the municipality level. To estimate equation (10), we take for each municipality the year in which the availability of Internet expanded the most. We then keep all municipalities with observations at least two years before and two years after to construct a balanced sample. We then run a basic gravity regression where we interact the gravity variables with dummies indicating year $s$ relative to the year of maximum expansion. This traces how the coefficients on all gravity variables vary relative to the year of the maximum expansion. We plot the estimation results for how the distance elasticity changes over time in Figure 4.

respect to origin size. While the OLS results are potentially biased, they are qualitatively in line with these intention-to-treat estimates to which we can give a causal interpretation.

\section{2SLS Estimates}

The intention-to-treat effects establish that expanding Internet coverage indeed affects the composition of trade by increasing the magnitudes of distance and size elasticities. Invoking the exclusion restriction, it is also possible to estimate how broadband Internet use (and not only coverage) affects the elasticity of trade with respect to distance. This means that we need to scale the broadband coverage effects up by the effect of coverage on take-up. We achieve this by estimating the first stages (4)-(7) using the survey information on firms' broadband adoption. Table 4 reports the results. The first thing to note is that the Sanderson-Windmeijer $F$-statistics (Sanderson and Windmeijer 2016) range from 12.5 for the first stage of the average broadband take-up rates in municipality $i, d_{i t}$, to more than 1,200 in the first stage that interacts $d_{i t}$ with (log of) distance. In the first column, we see that on average, expanding coverage by 10 percentage points increased take-up rates by about 2.2 percentage points. This effect is somewhat smaller in larger municipalities, and there is no heterogeneity in take-up with respect to the size and distance 
Table 4-First-Stage Regressions with Pair-Specific $(i \times j)$ Fixed Effects

\begin{tabular}{lcccc}
\hline \hline & $d_{i t}$ & $d_{i t} \times \log \left(\tau_{N O R, j t}\right)$ & $d_{i t} \times \log Y_{i t}$ & $d_{i t} \times \log Y_{j t}$ \\
& $(1)$ & $(2)$ & $(3)$ & $(4)$ \\
\hline $\log Y_{i t}$ & 0.064 & 0.064 & 0.552 & -0.214 \\
$\log Y_{j t}$ & $(0.155)$ & $(0.052)$ & $(0.205)$ & $(0.145)$ \\
& -0.017 & 0.196 & 0.116 & -0.410 \\
$z_{i t}$ & $(0.017)$ & $(0.024)$ & $(0.024)$ & $(0.071)$ \\
& 0.216 & -0.037 & -0.230 & 0.105 \\
$z_{i t} \times \log \left(\tau_{N O R, j t}\right)$ & $(0.052)$ & $(0.018)$ & $(0.097)$ & $(0.057)$ \\
& -0.003 & 0.707 & -0.006 & 0.031 \\
$z_{i t} \times \log Y_{i t}$ & $(0.008)$ & $(0.022)$ & $(0.011)$ & $(0.014)$ \\
$z_{i t} \times \log Y_{j t}$ & -0.038 & 0.004 & 0.713 & -0.022 \\
& $(0.025)$ & $(0.010)$ & $(0.036)$ & $(0.023)$ \\
$F$-statistic & 0.000 & 0.006 & 0.001 & 0.696 \\
Observations & $(0.004)$ & $(0.004)$ & $(0.006)$ & $(0.024)$ \\
& 12.5 & $1,257.3$ & 44.8 & $1,066.7$ \\
\hline
\end{tabular}

Notes: All regressions include fixed effects for year and municipality-country pairs. The sample period is 2001-2008. The sample consists of all municipality-country-year combinations where one trading partner is a Norwegian municipality and the other a country (not Norway) and where log value of trade is positive. The table reports the Sanderson-Windmeijer $F$-statistic. All reported standard errors are clustered at the municipality level.

to trade partners. Columns 2-4 report the first stages of the interaction between take-up and the gravity variables. Here we see that the only instruments that matter are the overall coverage rate $z_{i t}$ and the interaction between the coverage rate and the interacting gravity variable.

Column 5 in Table 3 reports the subsample IV estimation results of the augmented gravity equation in (3). The coefficient on Internet adoption is positive, pointing to a positive average effect of Internet adoption on trade. Behind this average, however, there is essential heterogeneity. Broadband Internet take-up increases the magnitude of the elasticity of trade with respect to distance by 0.17 and the elasticity of trade with respect to destination size by 0.09 . While qualitatively the same, these effects are larger than the OLS estimates. This suggests that municipalities with higher unobserved propensities to trade with remote and large destinations were more likely to adopt Internet. The evidence in Table 3 shows that Internet shifted trade toward closer destinations and toward larger trade partners. The point estimates suggest that broadband Internet adoption increased the magnitude of the elasticity of distance by 14 percent and the elasticity of destination size by 5 percent.

\section{E. Specification Checks}

The reduced-form and 2SLS estimates suggest that adoption of broadband Internet shifted trade toward closer destinations and toward larger trade partners. We now perform several specification checks to investigate the robustness of these results. 
Table 5-Gravity Estimation Results, Covariate Robustness-Trade Volume (log)

\begin{tabular}{|c|c|c|c|c|c|c|c|}
\hline & (1) & $(2)$ & (3) & (4) & $(5)$ & (6) & (7) \\
\hline \multicolumn{8}{|l|}{ Panel A. ITT } \\
\hline$z_{i t} \times \log \left(\tau_{N O R, j t}\right)$ & $\begin{array}{r}-0.119 \\
(0.035)\end{array}$ & $\begin{array}{r}-0.119 \\
(0.035)\end{array}$ & $\begin{array}{r}-0.120 \\
(0.034)\end{array}$ & $\begin{array}{r}-0.117 \\
(0.033)\end{array}$ & $\begin{array}{r}-0.107 \\
(0.033)\end{array}$ & $\begin{array}{r}-0.076 \\
(0.047)\end{array}$ & $\begin{array}{r}-0.071 \\
(0.047)\end{array}$ \\
\hline$z_{i t} \times \log Y_{j t}$ & $\begin{array}{c}0.064 \\
(0.017)\end{array}$ & $\begin{array}{c}0.064 \\
(0.017)\end{array}$ & $\begin{array}{c}0.065 \\
(0.016)\end{array}$ & $\begin{array}{c}0.061 \\
(0.017)\end{array}$ & $\begin{array}{c}0.048 \\
(0.017)\end{array}$ & $\begin{array}{c}0.057 \\
(0.023)\end{array}$ & $\begin{array}{c}0.064 \\
(0.023)\end{array}$ \\
\hline \multicolumn{8}{|l|}{ Panel B. SSIV } \\
\hline$d_{i t} \times \log \left(\tau_{N O R, j t}\right)$ & $\begin{array}{c}-0.171 \\
(0.045)\end{array}$ & $\begin{array}{c}-0.171 \\
(0.045)\end{array}$ & $\begin{array}{r}-0.172 \\
(0.044)\end{array}$ & $\begin{array}{r}-0.174 \\
(0.043)\end{array}$ & $\begin{array}{r}-0.156 \\
(0.042)\end{array}$ & $\begin{array}{r}-0.228 \\
(0.115)\end{array}$ & $\begin{array}{r}-0.210 \\
(0.121)\end{array}$ \\
\hline$d_{i t} \times \log Y_{j t}$ & $\begin{array}{c}0.094 \\
(0.022)\end{array}$ & $\begin{array}{c}0.093 \\
(0.022)\end{array}$ & $\begin{array}{c}0.094 \\
(0.021)\end{array}$ & $\begin{array}{c}0.091 \\
(0.021)\end{array}$ & $\begin{array}{c}0.072 \\
(0.021)\end{array}$ & $\begin{array}{c}0.168 \\
(0.059)\end{array}$ & $\begin{array}{c}0.181 \\
(0.059)\end{array}$ \\
\hline Pair FE & $\checkmark$ & $\checkmark$ & $\checkmark$ & $\checkmark$ & $\checkmark$ & $\checkmark$ & $\checkmark$ \\
\hline \multicolumn{8}{|l|}{ Time-varying covariates } \\
\hline $\begin{array}{l}\text { Demographic } \\
\text { Industry }\end{array}$ & & $\checkmark$ & $\begin{array}{l}\checkmark \\
\checkmark\end{array}$ & $\begin{array}{l}\checkmark \\
\checkmark\end{array}$ & $\begin{array}{l}\checkmark \\
\checkmark\end{array}$ & $\begin{array}{l}\checkmark \\
\checkmark\end{array}$ & $\begin{array}{l}\checkmark \\
\checkmark\end{array}$ \\
\hline $\begin{array}{l}\text { Trends interacted with } \\
\text { Baseline covariates } \\
\text { Municipality FE } \\
\text { Destination FE }\end{array}$ & & & & $\checkmark$ & $\checkmark$ & $\begin{array}{l}\checkmark \\
\checkmark\end{array}$ & $\checkmark$ \\
\hline Municipality-year FE & & & & & & & $\checkmark$ \\
\hline
\end{tabular}

Notes: $\tau=$ bilateral distance, $Y=$ economic size, $d=$ broadband adoption rate, $z=$ broadband coverage rate. Subscript $i$ refers to municipality, $j$ to destination/source country, and $t$ to year. All regressions include fixed effects for year and municipality-country-specific pairs. The sample period is 2001-2008. The sample consists of all municipality-country-year combinations where one trading partner is a Norwegian municipality and the other a country (not Norway) and where log value of trade is positive. Column 2 adds demographic controls to the baseline model, including municipality-level information on average household income, mean years of schooling, share of population residing in a densely populated locality, and size of population. Column 3 also includes industry controls, consisting of municipality averages of revenues, intermediates, capital stock, number of workers and wage bills as well as employment share in manufacturing, employment share in wholesale, employment share in transport/communication, and mean levels of export and import propensity and log export and import volumes. Column 4 interacts linear trends with baseline (year 2000) values of these covariates. Column 5 includes municipality-specific linear time trends. Column 6 includes both municipality-specific and destination-specific linear time trends. All reported standard errors are clustered at the municipality level. Column 7 adds municipality-year fixed effects to the specification with destination-specific linear trends.

The first set of robustness checks examines whether the timing of the broadband Internet rollout correlates with other time-varying covariates and/or trends. The results from regressions that may vary the set of controls are reported in 'Table 5. The first column repeats the baseline estimates from the reduced-form model. Columns 2 and 3 include a wide range of controls for the time-varying demographic and industry characteristics that we used in Section IIID to examine the determinants of the timing of the broadband rollout. As can be seen from the table, including these covariates barely moves the estimates of interest. In column 4, we include linear trends interacted with baseline (year 2000) demographic and industry covariates, while in column 5 we allow for municipality-specific linear trends. The coefficients barely move in any of these alternative specifications. In column 6, we include both municipality-specific and destination-specific linear trends (e.g., to capture changes in multilateral trade resistance over time). While we lose some precision as expected, the main results are not affected. We therefore conclude there is no evidence that our estimates are biased because the broadband Internet rollout correlated 
Table 6-Gravity Estimation Results, Sample Robustness-Trade Volume (log)

\begin{tabular}{|c|c|c|c|c|c|c|}
\hline & \multirow[b]{2}{*}{$\begin{array}{l}\text { Baseline } \\
\text { (1) }\end{array}$} & \multirow[b]{2}{*}{$\begin{array}{l}\text { Cond. on } 2000 \\
\text { (2) }\end{array}$} & \multicolumn{2}{|c|}{ Weights } & \multicolumn{2}{|c|}{ Number of largest cities excl. } \\
\hline & & & $\begin{array}{l}\text { Population } \\
\text { (3) }\end{array}$ & $\begin{array}{l}\text { GDP } \\
(4)\end{array}$ & $\begin{array}{c}3 \\
(5)\end{array}$ & $\begin{array}{l}5 \\
(6)\end{array}$ \\
\hline \multicolumn{7}{|l|}{ Panel A. ITT } \\
\hline$z_{i t} \times \log \left(\tau_{N O R, j t}\right)$ & $\begin{array}{c}-0.119 \\
(0.035)\end{array}$ & $\begin{array}{c}-0.171 \\
(0.038)\end{array}$ & $\begin{array}{c}-0.177 \\
(0.062)\end{array}$ & $\begin{array}{r}-0.188 \\
(0.067)\end{array}$ & $\begin{array}{c}-0.123 \\
(0.035)\end{array}$ & $\begin{array}{c}-0.127 \\
(0.035)\end{array}$ \\
\hline$z_{i t} \times \log Y_{j t}$ & $\begin{array}{c}0.064 \\
(0.017)\end{array}$ & $\begin{array}{c}0.102 \\
(0.018)\end{array}$ & $\begin{array}{c}0.041 \\
(0.028)\end{array}$ & $\begin{array}{c}0.042 \\
(0.029)\end{array}$ & $\begin{array}{c}0.068 \\
(0.017)\end{array}$ & $\begin{array}{c}0.071 \\
(0.017)\end{array}$ \\
\hline \multicolumn{7}{|l|}{ Panel B. SSIV } \\
\hline$d_{i t} \times \log \left(\tau_{N O R, j t}\right)$ & $\begin{array}{c}-0.171 \\
(0.045)\end{array}$ & $\begin{array}{c}-0.248 \\
(0.052)\end{array}$ & $\begin{array}{c}-0.222 \\
(0.066)\end{array}$ & $\begin{array}{r}-0.233 \\
(0.071)\end{array}$ & $\begin{array}{c}-0.178 \\
(0.045)\end{array}$ & $\begin{array}{c}-0.185 \\
(0.046)\end{array}$ \\
\hline$d_{i t} \times \log Y_{j t}$ & $\begin{array}{c}0.094 \\
(0.022)\end{array}$ & $\begin{array}{c}0.150 \\
(0.025)\end{array}$ & $\begin{array}{c}0.051 \\
(0.028)\end{array}$ & $\begin{array}{c}0.052 \\
(0.028)\end{array}$ & $\begin{array}{c}0.100 \\
(0.022)\end{array}$ & $\begin{array}{c}0.105 \\
(0.022)\end{array}$ \\
\hline Mean dep. var. & 10.96 & 11.79 & 10.96 & 10.96 & 10.89 & 10.87 \\
\hline Observations & 97,646 & 70,312 & 97,646 & 97,646 & 94,565 & 92,657 \\
\hline Pair FE & $\checkmark$ & $\checkmark$ & $\checkmark$ & $\checkmark$ & $\checkmark$ & $\checkmark$ \\
\hline
\end{tabular}

Notes: $\tau=$ bilateral distance, $Y=$ economic size, $d=$ broadband adoption rate, $z=$ broadband coverage rate. Subscript $i$ refers to municipality, $j$ to destination/source country, and $t$ to year. All regressions include fixed effects for year and municipality-country-specific pairs. The sample period is 2001-2008. The sample consists of all municipality-country-year combinations where one trading partner is a Norwegian municipality and the other a country (not Norway) and where log value of trade is positive. Column 2 restricts the sample to municipality-country pairs that report positive trade in 2000. Columns 3 and 4 weight observations by population and GDP, respectively, in the Norwegian municipality. In columns 5 and 6, we omit the three and five largest Norwegian cities, respectively. All reported standard errors are clustered at the municipality level.

with municipality or destination-specific trends in trade. Finally, in column 7 , we add municipality-year fixed effects to the specification destination-specific linear trends. The results do not change materially. ${ }^{17}$

The second set of robustness checks are presented in Table 6 . In these checks, we examine the sensitivity of our findings to the composition of our sample. For ease of reference, column 1 reports the estimates from our baseline specification. We start by investigating whether dynamics on the extensive margin (i.e., which municipality-country pairs engage in trade) matters for our conclusions. In column 2, we restrict the sample to the subsample of municipality-country pairs where trade also occurred in 2000 (the year before our sample period starts). The effects are qualitatively similar for this subsample, and, if anything, the Internet causes a somewhat larger change in the magnitudes of the elasticities with respect to trade and size of destination market.

The baseline results assign the same weight to each municipality-country pair. In columns 3 and 4, we report estimation results where we weight all observations by the number of inhabitants and the GDP of the Norwegian municipality, respectively.

\footnotetext{
${ }^{17}$ Since there is little if any variation across Norwegian municipalities in distances for a given destination, it is not possible to get reasonably precise estimates if we include controls for destination-time fixed effects. Our specification therefore lies between a standard gravity equation and what Head and Mayer (2014) refer to as a "naive" gravity model (which only includes country-specific fixed effects) as in the original work by Tinbergen (1962).
} 
TAble 7-Gravity Estimation Results for Import Volume $(\log )$

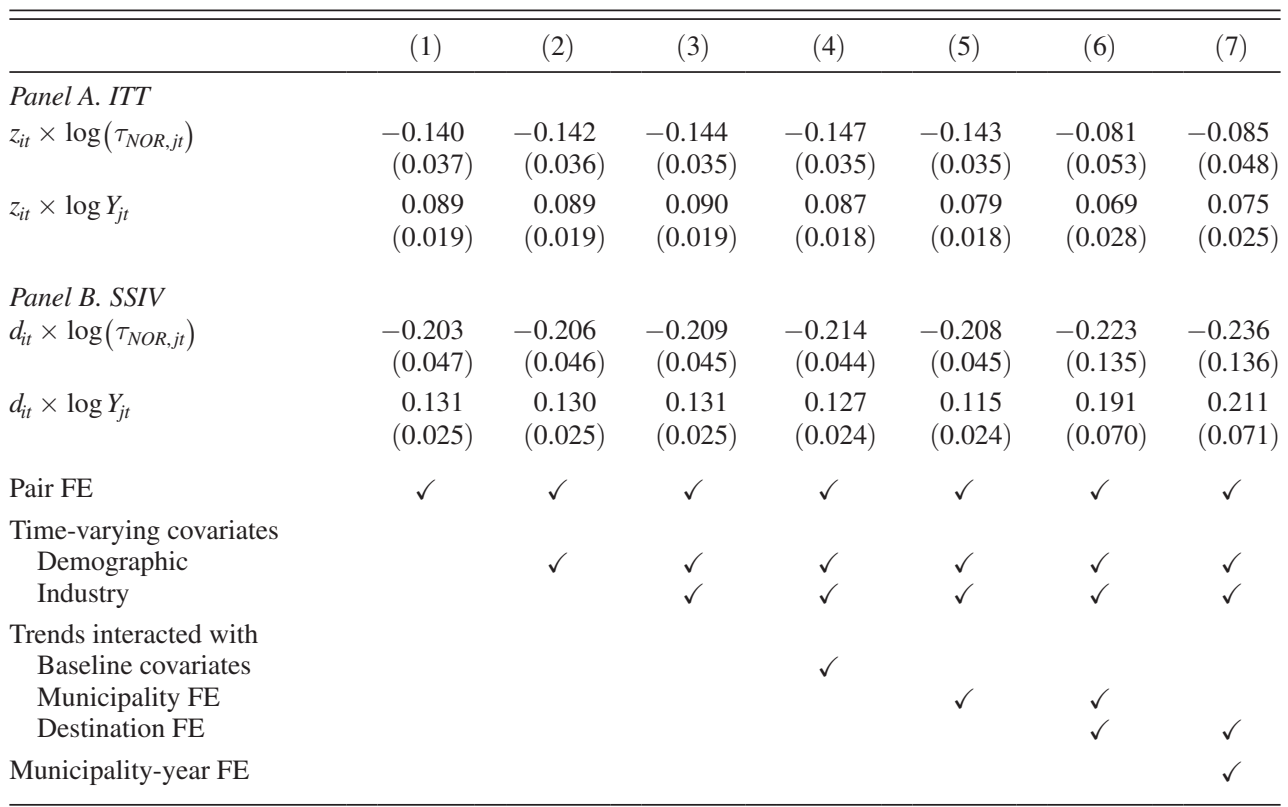

Notes: $\tau=$ bilateral distance, $Y=$ economic size, $d=$ broadband adoption rate, $z=$ broadband coverage rate. Subscript $i$ refers to municipality, $j$ to destination/source country, and $t$ to year. All regressions include fixed effects for year and municipality-country-specific pairs. The sample period is 2001-2008 and contains 78,196 observations. The sample consists of all municipality-country-year combinations where one trading partner is a Norwegian municipality and the other a country (not Norway) and where log value of import is positive. Column 2 adds demographic controls to the baseline model, including municipality-level information on average household income, mean years of schooling, share of population residing in a densely populated locality, and size of population. Column 3 also includes industry controls, consisting of municipality averages of revenues, intermediates, capital stock, number of workers and wage bills as well as employment share in manufacturing, employment share in wholesale, employment share in transport/communication, and mean levels of export and import propensity and $\log$ export and import volumes. Column 4 interacts linear trends with baseline (year 2000) values of these covariates. Column 5 includes municipality-specific linear time trends. Column 6 includes both municipality-specific and destination-specific linear time trends. All reported standard errors are clustered at the municipality level. Column 7 adds municipality-year fixed effects to the specification with destination-specific linear trends.

The results above confirm that adoption of broadband Internet shifted trade toward closer destinations and toward larger trade partners.

We documented above that the timing of the broadband Internet rollout correlated with degree of urbanity. In columns 5 and 6 , we examine the robustness of the results to removing the three and five largest cities in Norway, respectively. As can be seen in Table 6, removing the urban centers from the sample suggests that the correlation of the Internet rollout with urbanity does not change the conclusion adoption of broadband Internet shifted trade toward closer destinations and toward larger trade partners.

The final set of checks examine the robustness of our results if we restrict attention to imports only. The motivation for this check is that our theoretical model applies more directly to imports than exports. Table 7 presents the results. In this table, we perform the same regressions as in Table 5, except we change the dependent variable to import volume. The results do not materially change. This robustness is not 
surprising since the majority of trade for Norwegian municipalities, both in terms of total volumes and the number of firms that engage in trade, consists of importing.

\section{Mechanisms}

We have established that broadband Internet affects bilateral trade flows by making trade patterns more sensitive to distance. To better understand the channels through which broadband Internet affects trade patterns, we proceed to explore potential mechanisms in this section.

\section{A. Broadband Internet Makes Demand More Elastic by Reducing Information Friction}

One possible explanation for our findings is that broadband Internet reduces information frictions and increases the choice set of exporters and importers, making it easier to substitute if a specific market becomes more expensive to export to or import from. In online Appendix C, we formalize this argument in a model of international trade with variable elasticity of demand and information frictions. As explained in greater detail in the online Appendix, there are two essential features of the model. First, we follow Ottaviano, Tabuchi, and Thisse (2002) and Melitz and Ottaviano (2008) in using a linear demand system. ${ }^{18}$ As a result, demand becomes more elastic the more readily substitutes for the good can be obtained-a property of demand that can be traced back to Marshall's first rule of derived demand. Second, we model information frictions as restrictions on the access to markets with which a region can trade, similar to how Arkolakis (2010) views the role of marketing to reach foreign consumers.

Taken together, these two features give rise to a key prediction: adoption of a technology that lowers information frictions enlarges the choice set of exporters and importers and, therefore, increases the degree of competition. This makes demand more elastic with respect to bilateral trade costs and, as a consequence, increases the magnitude of the elasticity of trade with respect to distance.

The prediction of our model is consistent with previous work on the potential impact of the Internet on the distance elasticity. Freund and Weinhold (2004), for example, argue that if the Internet strengthens competition by reducing fixed costs of entry in export markets, then this will lead to greater import growth from more proximate countries, thereby increasing the effect of distance on trade. Our result is also in line with the prediction by Rauch and Trindade (2003), who argue that improvements in information can make variable trade costs more salient if home firms can more easily rule out potential foreign trade partners in advance of

\footnotetext{
${ }^{18}$ Linear demand is a special case of so-called "subconvex" demand systems, discussed in, for example, Mrázová and Neary (Mrázová and Neary 2014, 2017). Both Dixit and Stiglitz (1977) and Krugman (1979) argue that this type of demand system is economically appealing, and Zhelobodko et al. (2012) offer empirical support for such a specification of demand. Importantly, subconvexity rules out demand systems with constant elasticity of substitution. Novy (2013) uses a subconvex demand system to show how distance elasticities in international trade vary over time and countries.
} 
Table 8-Gravity Estimation, By Product Type-Trade Volume $(\log )$

\begin{tabular}{lcc}
\hline \hline & Homogeneous & Differentiated \\
& $(1)$ & $(2)$ \\
\hline Panel $A . I T T$ & -0.053 & -0.104 \\
$z_{i t} \times \log \left(\tau_{N O R, j t}\right)$ & $(0.061)$ & $(0.035)$ \\
$z_{i t} \times \log Y_{j t}$ & 0.002 & 0.086 \\
& $(0.029)$ & $(0.018)$ \\
Panel $B . S S I V$ & & -0.152 \\
$d_{i t} \times \log \left(\tau_{N O R, j t}\right)$ & -0.078 & $(0.045)$ \\
$d_{i t} \times \log Y_{j t}$ & $(0.075)$ & 0.125 \\
& 0.003 & $(0.024)$ \\
Mean dependent variable & $(0.037)$ & 10.63 \\
Observations & 10.80 & 87,426 \\
Pair fixed effects & 43,713 & $\checkmark$ \\
\hline
\end{tabular}

Notes: $\tau=$ bilateral distance, $Y=$ economic size, $d=$ broadband adoption rate, $z=$ broadband coverage rate. Subscript $i$ refers to municipality, $j$ to destination/source country, and $t$ to year. All regressions include fixed effects for year and municipality-country-specific pairs. The sample period is 2001-2008. The sample consists of all municipality-country-year combinations where one trading partner is a Norwegian municipality and the other a country (not Norway) and where log value of trade is positive. Products have been divided into homogeneous and differentiated according to the classification proposed in Rauch (1999). All reported standard errors are clustered at the municipality level.

attempting to form a match. The Internet in their framework can thus also increase the sensitivity of international trade to variable trade costs.

A corollary of our model's prediction is that the Internet-induced change in elasticities should be more pronounced for products for which information costs are more salient. Since information is arguably more important for trade in differentiated goods than for trade in homogeneous goods (as argued by Rauch 1999), we estimate the augmented gravity equations separately for trade flows in these two types of goods. Table 8 presents the results. Consistent with broadband Internet changing trade patterns through lowering information frictions, we find stronger effects of broadband adoption on the trade pattern of differentiated goods as compared to homogeneous goods.

\section{B. Alternative Mechanisms}

Although the comparative statics predictions are consistent with our empirical findings, it is important to observe that several mechanisms outside our model could also explain why adoption of broadband Internet increases the sensitivity of trade to distance.

One possible explanation is that the direct effect of Internet on bilateral trade flows may be stronger for destination countries with similar language (see, e.g., Blum and Goldfarb 2006). No other country has Norwegian as its main language, but English proficiency in other countries may play an important role due to the knowledge of English among Norwegians. If countries close to Norway are on 
Table 9-Gravity Estimation Results, Alternative MechanismsTrade Volume $(\log )$

\begin{tabular}{|c|c|c|c|}
\hline & \multirow[b]{2}{*}{$\begin{array}{c}\text { Baseline } \\
\text { (1) }\end{array}$} & \multicolumn{2}{|c|}{ Destination } \\
\hline & & $\begin{array}{c}\text { English } \\
\text { (2) }\end{array}$ & $\begin{array}{c}\text { Internet } \\
\text { (3) }\end{array}$ \\
\hline \multicolumn{4}{|l|}{ Panel A. ITT } \\
\hline$z_{i t} \times \log \left(\tau_{N O R, j t}\right)$ & $\begin{array}{r}-0.119 \\
(0.035)\end{array}$ & $\begin{array}{r}-0.143 \\
(0.055)\end{array}$ & $\begin{array}{r}-0.130 \\
(0.039)\end{array}$ \\
\hline$z_{i t} \times \log Y_{j t}$ & $\begin{array}{c}0.064 \\
(0.017)\end{array}$ & $\begin{array}{c}0.070 \\
(0.021)\end{array}$ & $\begin{array}{c}0.073 \\
(0.016)\end{array}$ \\
\hline \multicolumn{4}{|l|}{ Panel B. SSIV } \\
\hline$d_{i t} \times \log \left(\tau_{N O R, j t}\right)$ & $\begin{array}{r}-0.171 \\
(0.045)\end{array}$ & $\begin{array}{r}-0.205 \\
(0.070)\end{array}$ & $\begin{array}{r}-0.191 \\
(0.052)\end{array}$ \\
\hline$d_{i t} \times \log Y_{j t}$ & $\begin{array}{c}0.094 \\
(0.022)\end{array}$ & $\begin{array}{c}0.105 \\
(0.028)\end{array}$ & $\begin{array}{c}0.104 \\
(0.021)\end{array}$ \\
\hline Mean dependent variable & 10.96 & 11.18 & 10.97 \\
\hline Observations & 97,646 & 73,274 & 97,207 \\
\hline Pair fixed effects & $\checkmark$ & $\checkmark$ & $\checkmark$ \\
\hline
\end{tabular}

Notes: $\tau=$ bilateral distance, $Y=$ economic size, $d=$ broadband adoption rate, $z=$ broadband coverage rate. Subscript $i$ refers to municipality, $j$ to destination/source country, and $t$ to year. All regressions include fixed effects for year and municipality-country-specific pairs. The sample period is 2001-2008. The sample consists of all municipality-country-year combinations where one trading partner is a Norwegian municipality and the other a country (not Norway) and where log value of trade is positive. Column 2 includes also English proficiency and its interaction with Internet. Column 3 adds destination-level Internet usage and its interaction with Internet. All reported standard errors are clustered at the municipality level.

average more proficient in English than countries further away, then this might be the reason why the Internet generates more trade with countries closer than further away. We use the English Proficiency Index for 71 countries as measured by the language teaching firm Education First and include this as a control variable in our regressions, as well as this variable interacted with Internet. Column 2 in Table 9 reports the results, while column 1 repeats our baseline specification. We find that adding these controls barely moves the estimated coefficient on the interaction term between broadband and destination market size, whereas the estimated coefficient on the interaction term between broadband and distance does not change materially.

Another possibility is that the direct effect of Internet on bilateral trade flows may be stronger if the destination countries themselves have high Internet penetration (see, e.g., the theory of two-sided markets of Rochet and Tirole 2006). Empirically, countries closer to Norway tend to have higher Internet penetration. To examine this mechanism, we use estimates from the World Bank on Internet penetration and include this variable as well as its interaction with Internet into our baseline regression. Column 3 in Table 9 shows that adding these controls does not substantially change the estimated coefficient on the interaction term between broadband and destination market size or the estimated coefficient on the interaction term between broadband and distance. 


\section{Conclusion}

Recent work suggests the patterns of international trade may be distorted because of information frictions. Little is known, however, about how advancements in information communication technology affect trade patterns. The goal of our paper was to analyze how and why the adoption of such technology affects bilateral trade flows.

The context of our study is the adoption of broadband Internet in Norwegian firms over the period 2000-2008. We used panel data with information on Norwegian firms with regards to their production, technology, and trade. A public program with limited funding rolled out broadband access points and provided plausibly exogenous variation in the availability and adoption of broadband Internet in firms. We found that adoption of broadband Internet makes trade patterns more sensitive to distance and economic size. Going from no broadband availability to full coverage increases the magnitude of the elasticity of trade with respect to distance by 0.12 and the elasticity of trade with respect to destination size by 0.06 . For distance, this means that an increase in Internet availability of 10 percentage points increases trade for a country at the twenty-fifth distance percentile by 1.1 percent more than for a country at the seventy-fifth distance percentile. The same difference for the GDP of a destination is 2.1 percent.

We interpreted the empirical results through a model of international trade with variable elasticity of demand and information frictions. We provided comparative statics predictions with respect to a reduction in information frictions and showed that these predictions are consistent with our empirical findings. We also considered alternative mechanisms outside the model that, in principle, could also explain why adoption of broadband Internet increases the sensitivity of trade to distance. However, the data are at odds with these alternative mechanisms.

Taken together, our results point to the importance of incorporating information frictions in the frequently used gravity equation of trade. Moreover, our study offers a possible explanation for the so-called "distance puzzle," which is that the magnitude of the distance coefficient in gravity equations has changed little or increased over time, despite the significant advancements in globalization and ICT. We provided both theory and evidence suggesting that adoption of a technology that lowers information frictions actually increases the magnitude of the elasticity of trade with respect to distance.

\section{REFERENCES}

Ahn, JaeBin, Amit K. Khandelwal, and Shang-Jin Wei. 2011. "The Role of Intermediaries in Facilitating Trade." Journal of International Economics 84 (1): 73-85.

-Akerman, Anders, Ingvil Gaarder, and Magne Mogstad. 2015. "The Skill Complementarity of Broadband Internet.” Quarterly Journal of Economics 130 (4): 1781-1824.

Akerman, Anders, Edwin Leuven, and Magne Mogstad. 2022. "Replication data for: Information Frictions, Internet, and the Relationship between Distance and Trade." American Economic Association [publisher], Inter-university Consortium for Political and Social Research [distributor]. https://doi. org/10.3886/E121602V1.

Allen, Treb. 2014. "Information Frictions in Trade." Econometrica 82 (6): 2041-83. 
Angrist, Joshua D., and Alan B. Krueger. 1995. "Split-Sample Instrumental Variables Estimates of the Return to Schooling." Journal of Business and Economic Statistics 13 (2): 225-35.

-Antràs, Pol, and Arnaud Costinot. 2011. "Intermediated Trade." Quarterly Journal of Economics $126(3): 1319-74$.

Arkolakis, Costas. 2010. "Market Penetration Costs and the New Consumers Margin in International Trade." Journal of Political Economy 118 (6): 1151-99.

Baldwin, Richard E., and Daria Taglioni. 2006. "Gravity for Dummies and Dummies for Gravity Equations." NBER Working Paper 12516.

Beaudry, Paul, Mark Doms, and Ethan Lewis. 2010. "Should the Personal Computer Be Considered a Technological Revolution? Evidence from US Metropolitan Areas.” Journal of Political Economy 118 (5): 988-1036.

Beaudry, Paul, and David A. Green. 2003. "The Changing Structure of Wages in the US and Germany: What Explains the Differences?" American Economic Review 93 (3): 573-602.

Beaudry, Paul, and David A. Green. 2005. "Changes in US Wages, 1976-2000: Ongoing Skill Bias or Major Technological Change?" Journal of Labor Economics 23 (3): 609-48.

Berthelon, Matias, and Caroline L. Freund. 2008. "On the Conservation of Distance in International Trade." Journal of International Economics 75: 310-20.

Bhuller, Manudeep, Tarjei Havnes, Edwin Leuven, and Magne Mogstad. 2013. "Broadband Internet: An Information Superhighway to Sex Crime?" Review of Economic Studies 80 (4): 1237-66.

Blum, Bernardo S., and Avi Goldfarb. 2006. "Does the Internet Defy the Law of Gravity?" Journal of International Economics 70 (2): 384-405.

Cairncross, Frances. 1997. The Death of Distance: How the Communications Revolution Will Change Our Lives. Boston: Harvard Business School Press.

Choi, Changkyu. 2010. "The Effect of the Internet on Service Trade." Economics Letters 109 (2): 102-04.

Coe, David T., Arvind Subramanian, Natalia T. Tamirisia, and Rikhil R Bhavnani. 2002. "The Missing Globalization Puzzle.’ IMF Working Paper 02/171.

-Dasgupta, Kunal, and Jordi Mondria. 2018. “Inattentive Importers.” Journal of International Economics 112: 150-65.

Dickstein, Michael J., and Eduardo Morales. 2018. "What Do Exporters Know?" Quarterly Journal of Economics 133 (4): 1753-801.

Disdier, Anne-Célia, and Keith Head. 2008. "The Puzzling Persistence of the Distance Effect on Bilateral Trade." Review of Economics and Statistics 90 (1): 37-48.

Dixit, Avinash K., and Joseph E. Stiglitz. 1977. "Monopolistic Competition and Optimum Product Diversity." American Economic Review 67 (3): 297-308.

-Freund, Caroline L., and Diana Weinhold. 2004. "The Effect of the Internet on International Trade." Journal of International Economics 62 (1): 171-89.

Friedman, Thomas. 2005. The World Is Flat: A Brief History of the Twenty-First Century. New York: Farrar, Straus and Giroux.

Head, Keith, and Thierry Mayer. 2014. “Gravity Equations: Workhorse, Toolkit, Cookbook.” In Handbook of International Economics, Vol. 4, edited by Gita Gopinath, Elhanan Helpman and Kenneth Rogoff, 131-95. Amsterdam: North-Holland.

Hortaçsu, Ali, F. Asís Martínez-Jerez, and Jason Douglas. 2009. "The Geography of Trade in Online Transactions: Evidence from eBay and MercadoLibre." American Economic Journal: Microeconomics 1 (1): 53-74.

-Inoue, Atsushi, and Gary Solon. 2010. “Two-Sample Instrumental Variables Estimators.” Review of Economics and Statistics 92 (3): 557-61.

-Krugman, Paul R. 1979. "Increasing Returns, Monopolistic Competition, and International Trade." Journal of International Economics 9 (4): 469-79.

Leamer, Edward E. 2007. "A Flat World, a Level Playing Field, a Small World After All, or None of the Above? A Review of Thomas L. Friedman's The World Is Flat." Journal of Economic Literature 45 (1): 83-126.

Lendle, Andreas, Marcelo Olarreaga, Simon Schropp, and Pierre-Louis Vézina. 2015. "There Goes Gravity: eBay and the Death of Distance." Economic Journal 126 (591): 406-41.

Mayer, Thierry, and Soledad Zignago. 2011. "Notes on CEPII's Distances Measures: The GeoDist Database." CEPII Working Paper 2011-25.

-Melitz, Marc J., and Gianmarco I.P. Ottaviano. 2008. "Market Size, Trade, and Productivity." Review of Economic Studies 75 (1): 295-316. 
Mrázová, Monika, and J. Peter Neary. 2014. "Together at Last: Trade Costs, Demand Structure, and Welfare." American Economic Review 104 (5): 298-303.

-Mrázová, Monika, and J. Peter Neary. 2017. "Not So Demanding: Demand Structure and Firm Behavior." American Economic Review 107 (12): 3835-74.

- Novy, Dennis. 2013. "International Trade without CES: Estimating Translog Gravity." Journal of International Economics 89 (2): 271-82.

Dottaviano, Gianmarco I.P., Takatoshi Tabuchi, and Jacques-François Thisse. 2002. "Agglomeration and Trade Revisited." International Economic Review 43 (2): 409-35.

-Rauch, James E. 1999. "Networks versus Markets in International Trade." Journal of International Economics 48 (1): 7-35.

- Rauch, James E., and Vitor Trindade. 2002. "Ethnic Chinese Networks in International Trade." Review of Economics and Statistics 84 (1): 116-30.

- Rauch, James E., and Vitor Trindade. 2003. "Information, International Substitutability, and Globalization." American Economic Review 93 (3): 775-91.

-Rochet, Jean-Charles, and Jean Tirole. 2006. "Two-Sided Markets: A Progress Report." RAND Journal of Economics 37 (3): 645-67.

-Sanderson, Eleanor, and Frank Windmeijer. 2016. "A Weak Instrument F-Test in Linear IV Models with Multiple Endogenous Variables." Journal of Econometrics 190 (2): 212-21.

Tinbergen, Jan. 1962. Shaping the World Economy: Suggestions for an International Economic Policy. New York: Twentieth Century Fund.

UNESCO. 2012. The State of Broadband 2012: Achieving Digital Inclusion for All. New York: Broadband Commission for Digital Development.

-Yeung, Patrick. 1972. "A Note on the Rules of Derived Demand." Quarterly Journal of Economics 86 (3): 511-17.

-Yotov, Yoto V. 2012. “A Simple Solution to the Distance Puzzle in International Trade." Economics Letters 117 (3): 794-98.

Zhelobodko, Evgeny, Sergey Kokovin, Mathieu Parenti, and Jacques-François Thisse. 2012. "Monopolistic Competition: Beyond the Constant Elasticity of Substitution." Econometrica 80 (6): 2765-84. 